\title{
PROJECT
}

\section{New Catalysts for Direct Methanol Oxidation Fuel Cells}

Principal Investigator: Radoslav Adzic Signature: Rodost $\checkmark$ fortć

Staff: N. Marinkovic

Partner: International Fuel Cells Corporation, Inc.

Final Report

Project Duration: May 1995-May 1998 


\section{DISCLAIMER}

This report was prepared as an account of work sponsored by an agency of the United States Government. Neither the United States Government nor any agency thereof, nor any of their employees, make any warranty, express or implied, or assumes any legal liability or responsibility for the accuracy, completeness, or usefulness of any information, apparatus, product, or process disclosed, or represents that its use would not infringe privately owned rights. Reference herein to any specific commercial product, process, or service by trade name, trademark, manufacturer, or otherwise does not necessarily constitute or imply its endorsement, recommendation, or favoring by the United States Government or any agency thereof. The views and opinions of authors expressed herein do not necessarily state or reflect those of the United States Government or any agency thereof. 


\section{DISCLAIMER}

Portions of this document may be illegible in electronic image products. Images are produced from the best available original document. 


\section{Abstract}

A new class of efficient electrocatalytic materials based on platinum - metal oxide systems has been synthetized and characterized by several techniques. Best activity was found with $\mathrm{NiWO}_{4-}^{-}, \mathrm{CoWO}_{4-}$, and $\mathrm{RuO}_{2-}$ supported platinum catalysts. A very similar activity at room temperature was observed with the electrodes prepared with the catalyst obtained from International Fuel Cells Inc. for the same Pt loading. Surprisingly, the two tungstates per se show a small activity for methanol oxidation without any $\mathrm{Pt}$ loading. Synthesis of $\mathrm{NiWO}_{4}$ and $\mathrm{CoWO}_{4}$ were carried out by solid-state reactions. FTIR spectroscopy shows that the tungstates contain a certain amount of physically adsorbed water even after heating samples at $200^{\circ} \mathrm{C}$. A direct relationship between the activity for methanol oxidation and the amount of adsorbed water on those oxides has been found. The $\mathrm{Ru}(0001)$ single crystal shows a very small activity for $\mathrm{CO}$ adsorption and oxidation, in contrast to the behavior of polycrystalline $\mathrm{Ru}$.

In situ extended x-ray absorption fine structure spectroscopy (EXAFS) and x-ray absorption near edge spectroscopy (XANES) showed that the $\mathrm{OH}$ adsorption on $\mathrm{Ru}$ in the Pt-Ru alloy appears to be the limiting step in methanol oxidation. This does not occur for $\mathrm{Pt}-\mathrm{RuO}_{2}$ electrocatalyst, which explains its advantages over the Pt-Ru alloys. The IFCC electrocatalyst has the properties of the Pt-Ru alloy. 


\section{Project Objectives}

There were two objectives of this project. The first was to synthesize and characterize a new class of efficient electrocatalytic materials based on platinum - metal oxide systems. The second one was to clarify the difference in the behavior of the Pt-Ru alloy and Pt-Ru oxide electrocatalysts, since the first one has been the best electrocatalyst system commercially available so far and there were indications that the other offered some improvement.

Methanol as a potential fuel in fuel cells brings about several advantages over hydrogen, including storage capacity, specific cost and safety of use. However, the key problem in developing of methanol fuel cells is the inadequate activity of the anode catalyst. Metallic platinum is sufficiently active for a partial oxidation of methanol. Its surface, however, becomes rapidly blocked with the strongly bound products of this partial oxidation, predominantly carbon monoxide (CO). Further oxidation of $\mathrm{CO}$ to $\mathrm{CO}_{2}$ requires a reaction of $\mathrm{CO}$ with oxygen-containing species. These species are formed in oxidation of water on platinum, for which a substantial overpotential is required. Ruthenium is oxidized to $\mathrm{RuOH}$ on more negative potentials so that the oxidation of $\mathrm{CO}$ to $\mathrm{CO}_{2}$ on Pt-Ru alloys occurs at lower potentials. However, the activity of Pt-Ru alloy systems is still unsatisfactory and their cost appears prohibitively high. Improvement of the activity of electrocatalysts and decreasing their load are needed before the commercialization of the direct methanol fuel cells becomes feasible. 
The initial step in methanol oxidation on $\mathrm{Pt}$ is the adsorption of the organic molecule on the catalyst's surface. In our view, alloying platinum with ruthenium changes the electronic property of platinum, making it less active for the adsorption of methanol, the first critical step of the reaction. On the other hand, it was expected that supporting $\mathrm{Pt}$ on metal oxide surfaces should not cause a pronounced change of the electronic properties of platinum since the catalyst-support interactions are usually less strong than the interactions of the alloying components. Therefore, the change in the electronic properties of $\mathrm{Pt}$ is expected to be decreased which would prevent a loss of activity for methanol adsorption caused by alloying. The oxygen-containing species, necessary for $\mathrm{CO}$ oxidation, would be supplied from hydroxyl or water strongly interacting with the oxide surfaces. The "spillover" of $\mathrm{CO}$ to $\mathrm{M}-\mathrm{OH}$ or $\mathrm{M}-\mathrm{H}_{2} \mathrm{O}_{2 \mathrm{ds}}$, or of $\mathrm{OH}$ to $\mathrm{Pt}$ sites, is expected to occur to make this reaction possible. The consumed oxygen-containing species could be easily replenished by reaction of the oxide surface with water.

\section{Selection and Synthesis of Oxides}

Several metal oxides were tested during this project. For selecting a potential candidate, the following factors were taken into account: first, the oxide has to be stable in strongly acidic solution. Further, the oxide needs to be able to provide the oxygen (in form of $\mathrm{OH}$ or $\mathrm{H}_{2} \mathrm{O}_{\text {ads }}$ ) and finally, it needs to readily readsorb $\mathrm{H}_{2} \mathrm{O}$ or $\mathrm{OH}$. After initial screening, several transition-metal oxides, mixed oxides and one chalchogenide were selected. Most oxides were purchased (Aldrich, CERAC) and used without further refining. Some of potentially good candidates, unavailable from external sources, were synthesized. 
The best results were obtained with $\mathrm{NiWO}_{4}$ and $\mathrm{CoWO}_{4}$ compounds and both, commercial and synthesizes samples of these oxides were tested. Synthesis of $\mathrm{NiWO}_{4}$ and $\mathrm{CoWO}_{4}$ were carried out by solid-state reactions of corresponding metal nitrates and ammonium tungstate, at temperatures lower than that used in commercial synthesis. This procedure yields a smaller grain particle size of the oxides and improves the electrochemical activity of the oxide substrate for methanol oxidation, as shown below.

\section{Characterization}

Physical methods:

Synthesized oxides were characterized by $\mathbf{x}$-ray diffraction to confirm their structure. It has been found that the synthesis of nickel and cobalt tungstates can proceed at $600{ }^{\circ} \mathrm{C}$. X-ray diffraction spectrum shows that the obtained powder is over $99 \% \mathrm{NiWO}_{4}$ (or $\mathrm{CoWO}_{4}$ ). The impurities, mostly $\mathrm{NiO}$ or $\mathrm{CoO}$ that have not been reacted, can be easily dissolved in $\mathrm{H}_{2} \mathrm{SO}_{4}$. After the cleaning $\mathrm{x}$-ray diffraction reveals no trace impurities, producing a spectrum identical to that of commercial tungstates.

BET gas adsorption data were used to measure the average particle diameter of the oxides. It was shown that the electrochemical activity of these oxides depends inversely on the particle size. Synthesized oxide particles were shown to have several times smaller diameter than that of commercial samples. Combining the synthesis procedure with ball milling, oxide particles of $0.3 \mu \mathrm{m}$ in diameter were obtained. 


\section{Electrode preparation;}

The electrodes were prepared by chemical or electrochemical deposition of $\mathrm{Pt}$ particles on the substrate. For oxide support, an appropriate amount of $\mathrm{Pt}$ in the form of $\mathrm{H}_{2} \mathrm{PtCl}_{6}$ was added, followed by the reduction of $\mathrm{Pt}$ by a reduction agents $\left(\mathrm{NaBH}_{4}, \mathrm{H}_{2}\right.$ or citric acid). The best results were obtained by reduction with a dilute solution ( $0.01 \mathrm{M})$ of $\mathrm{NaBH}_{4}$ with strong agitation. $\mathrm{Pt} / \mathrm{RuO}_{2}$ electrodes were prepared by mixing appropriate concentrations of $\mathrm{H}_{2} \mathrm{PtCl}_{6}$ and $\mathrm{RuCl}_{3}$ in $50 \%$ alcohol, followed by adding the solution dropwise into a cooled alkaline solution of $\mathrm{NaBH}_{4}$ with strong agitation.

The powdered catalysts were mixed with an appropriate amount of carbon (Vulcan X75), previously mixed with Teflon ( $37 \%$ wt.) and pressed onto a nickel net with electrochemically deposited gold film, or onto a gold thin sheet. Before pressing, each gold-covered nickel net was electrochemically tested in a acidic methanol solution for stability of the gold thin layer. Since gold has no oxidation capability for the methanol oxidation, if a current other than charging of the double layer is detected, such a gold/nickel net was discarded.

\section{Electrochemical measurements:}

Electrochemical techniques were used to determine the activity of prepared electrocatalysts. Kinetics of methanol oxidation has been measured with the prepared electrodes and their activity compared with the activity of the samples obtained from IFCC. Electrochemical activities of these oxides were checked before deposition of Pt. Various loads of $\mathrm{Pt}$ on several oxides and $\mathrm{Pt}$ supported on mixed oxides were studied. Best activity was found with $\mathrm{NiWO}_{4-}^{-}, \mathrm{CoWO}_{4}$, and $\mathrm{RuO}_{2-}$ supported platinum catalysts. 
Surprisingly, the two tungstates per se show a small activity for methanol oxidation without any $\mathrm{Pt}$ loading. Figure 1 shows the electrochemical oxidation of methanol on NiWO $\mathrm{O}_{4}$. The oxidation starts at $0.6 \mathrm{~V}$, i.e. at the potential close to the one found for a platinum electrode. Although the activity is low, this finding demonstrates that $\mathrm{NiWO}_{4}$ can be an interesting support. This also indicates that further study of oxides as supports for $\mathrm{Pt}$ may be promising.

Figure 2 shows the oxidation of methanol on samples prepared by dispersing platinum particles on commercial $\mathrm{NiWO}_{4}$ (particle size of $45 \mu \mathrm{m}$ ) and on synthesized $\mathrm{NiWO}_{4}$. The latter was ball milled down to the particle size $0.3 \mu \mathrm{m}$. The sweep in anodic direction is only shown. It is seen that the onset of methanol oxidation strongly depends on the particle size of tungstate. The samples with smaller grains have the onset of methanol oxidation shifted by $120 \mathrm{mV}$ to the less positive potentials. The current density of over $100 \mathrm{~mA} / \mathrm{cm}^{2}$ is reached at $0.6 \mathrm{~V}$. Further refinement of the particle size of the tungstate is likely to shift the onset of oxidation to even lower potentials. With further optimization of the system, in particular of the electrode structure, an increase in the activity can be expected and the Pt-metal oxide samples can probably reach or surpass the activity of Pt-Ru alloys:

Further improvement of the methanol oxidation kinetics was achieved by mixing $\mathrm{NiWO}_{4}$ with $0.3 \mu \mathrm{m} \mathrm{RuO}$ and Pt. Figure 3 shows that the current density of the order of $150 \mathrm{~mA} / \mathrm{cm}^{2}$ can be obtained at $0.6 \mathrm{~V}$ with a sample consisting of $90 \% \mathrm{NiWO}_{4}, 10 \% \mathrm{RuO}_{2}$ and Pt. A very similar activity at room temperature was observed with the electrodes prepared with the catalyst obtained from IFCC for the same Pt loading. At somewhat more positive potentials, the oxide-supported catalysts show even slightly better activities. 
This finding prompted investigation of the $\mathrm{Pt}^{-\mathrm{RuO}_{2}}$ electrodes by electrochemical and XANES techniques (vide infra).

\section{Spectroscopic measurements:}

FTIR: Fourier transform infrared spectroscopy was used to confirm that water strongly interacts with the $\mathrm{NiWO}_{4}$ and $\mathrm{CoWO}_{4}$ oxide surfaces. The attenuated total reflection configuration was used for studying high area oxide surfaces. It was shown that the tungstates contain a certain amount of physically adsorbed water even after heating samples at $200{ }^{\circ} \mathrm{C}$. For several samples investigated there was a direct relationship between the activity for methanol oxidation and the amount of adsorbed water on those oxides. This information is relevant for the function of the oxides as a support for Pt in methanol oxidation and confirms the validity of our approach to the problem.

In situ infrared spectroscopy was also used to study methanol and $\mathrm{CO}$ oxidation on platinum covered by a submonolayer of ruthenium and on ruthenium electrodes. The spectra obtained on polycrystalline $\mathrm{Ru}$ and Pt confirm electrochemical data regarding the onset potential of the $\mathrm{CO}$ oxidation. In methanol oxidation on submonolayer coverages of

$\mathrm{Ru}$ on $\mathrm{Pt}$, in addition to adsorbed $\mathrm{CO}$, adsorbed carboxylic species have been observed. Some experiments were also conducted with a well-ordered single crystal $R u(0001)$ surface and compared with the data for polycrystalline $\mathbb{R u}$ and with $\operatorname{Pt}(111)$ which has the same hexagonal arrangement of atoms at the surface the $\mathrm{Ru}(0001)$ surface. While both polycrystalline $\mathrm{Pt}$ and $\mathrm{Pt}(111)$, as well as polycrystalline nuthenium, show an appreciable activity toward $\mathrm{CO}$ oxidation, the surface of the $\mathrm{Ru}(0001)$ single crystal shows a very 
small activity. This was found by electrochemical techniques and confirmed by IR data. SNIFTIR spectra for the $\mathrm{CO}$ oxidation on $\mathrm{Ru}($ poly) and $\mathrm{Ru}(0001)$ are presented in Figs. $4 \mathrm{a}$ and $4 \mathrm{~b} . \mathrm{CO}$ is strongly bound on $\mathrm{Ru}($ poly) until the potential of about $0.3 \mathrm{~V}$, indicated by the strong, bipolar-shaped band with a maximum at $\sim 2000 \mathrm{~cm}^{-1}$, Fig. 4a. At more positive potentials $\mathrm{CO}$ is oxidized and the $\mathrm{CO}$ coverage decreases. At the same time a strong, narrow band at $2340 \mathrm{~cm}^{-1}$, due to the solvated $\mathrm{CO}_{2}$ is observed. On the other hand, the coverage of $\mathrm{CO}$ is hardly observable on $\mathrm{Ru}(0001)$ at all potentials, and consequently no $\mathrm{CO}_{2}$ could be detected in the spectrum, Fig. $4 \mathrm{~b}$. This finding warrants further study of the role of the $\mathrm{Ru}$ orientation for $\mathrm{CO}$ adsorption and in determining the activity of the Pt-Ru systems.

$X$-ray adsorption studies: In situ extended x-ray absorption fine structure spectroscopy (EXAFS) and x-ray absorption near edge spectroscopy (XANES) showed that there is an important difference in the behaviors of the Pt-Ru alloys and $\mathrm{Pt}-\mathrm{RuO}_{2}$ electrocatalysts. In situ XANES spectroscopy by measuring the platinum $\mathrm{L}_{3}$ edge showed a strong interaction between the two metals in the alloy, while the Pt-RuO $\mathrm{R}_{2}$ sample had a much lower perturbation of $\mathrm{Pt}$. This observation confirms our previous interpretation of electrochemical data involving the changes of the methanol adsorption on Pt upon alloying. In addition, by measuring the ruthenium edge during the course of methanol oxidation, the changes in ruthenium oxidation state was observed and the behavior of the two systems compared. Important difference in the behavior of $\mathrm{Pt}-\mathrm{Ru}$ alloys and $\mathrm{Pt}-\mathrm{RuO} 2$ system during methanol oxidation have been demonstrated. Figure 5 shows the comparison of the ruthenium edge XANES spectra on the Pt-Ru alloy and Pt-RuO 
samples at different electrode potentials. At the most negative potentials $(0.0 \mathrm{~V})$, both samples show that ruthenium is oxidized. At $0.54 \mathrm{~V}$, where methanol oxidation current densities are substantial for both samples, the Pt-Ru alloy sample shows that ruthenium oxidation state is close to the metallic $\mathrm{Ru}$. On the other hand, the $\mathrm{Pt}^{-\mathrm{RuO}_{2}}$ catalyst shows no such limitation, as the surface oxygen-containing species are readily available on the $\mathrm{RuO}_{2}$ surface and no decrease in the $\mathrm{Ru}-\mathrm{OH}$ signature in spectra was observed. Therefore, the $\mathrm{OH}$ adsorption on $\mathrm{Ru}$ in the Pt-Ru alloy appears to be the limiting step in methanol oxidation. As it can be seen from Fig. 5, the three curves for methanol oxidation on the $\mathrm{Pt} / \mathrm{RuO}_{2}$ sample at three different potentials lie below the $\mathrm{Ru}$ black standard, confirming that the Ru oxidation state is practically unchanged during the methanol oxidation. This difference in the behavior of the two catalysts explains the advantages of the $\mathrm{Pt}^{-\mathrm{RuO}_{2}}$ electrodes over Pt-Ru alloys, observed in the electrochemical measurements at higher positive potentials (see Fig. 3). These results show that the $\mathrm{RuO}_{2}$ supported $\mathrm{Pt}$ is a better electrocatalyst for methanol oxidation than the Pt-Ru alloys.

The IFCC electrocatalyst has been characterized by both, XANES and EXAFS techniques. The results that the IFCC electrocatalyst has properties of the Pt-Ru alloy.

\section{Significant Accomplishments}

A synthesis of a new class of catalysts for direct methanol fuel cells based on the Pt-metal oxides systems has been realized. The activity of the Pt-NiWO4 and Pt-CoWO 4 electrocatalysts is not only comparable but is higher at larger overpotentials than that of commercial sampies. These electrocatalysts have not been optimized. There is a possibility for further improvement, in particular regarding grain size of the support and the electrode 
structure. This indicates the Pt-metal oxide systems should be further explored. The system with mixed oxides, containing $5-10 \%$ of $\mathrm{Ru}_{2} \mathrm{O}$, shows even better characteristics. The amount of ruthenium is substantially reduced, if not completely eliminated, with respect to the best $\mathrm{Pt}-\mathrm{Ru}$ alloy catalysts containing $50 \% \mathrm{Ru}$.

The results of the project demonstrated that the $\mathrm{Pt}-\mathrm{RuO}_{2}$ electrocatalysts have advantages over the $\mathrm{Pt}-\mathrm{Ru}$ alloy electrocatalysts and explained the difference in the behavior on the basis of the XANES and EXAFS data.

FTIR spectroscopy measurements demonstrated that adsorbed $\mathrm{H}_{2} \mathrm{O}$ layers are present on surfaces of some oxides even after heating at $200{ }^{\circ} \mathrm{C}$. Activity of oxidesupported Pt electrocatalysts for methanol oxidation is related to the amount of adsorbed water. In situ FTIR spectroscopy measurements revealed that there is a relationship between the $\mathrm{Ru}$ surface orientation and the amount of adsorbed $\mathrm{CO}$. Both information indicate that these are directions for future studies of electrocatalysts for methanol oxidation.

\section{Significant Problems}

The major problem in the project was to synthesize the micro particles of $\mathrm{Ni}$ - or Co-tungstates. The results indicate that the catalytic activity can be considerably increased with further decrease of the particle size of these oxides. That, however, could not be obtained by simple ball-milling procedure used and requires a considerable synthetic effort. 


\section{Industry Benefits}

Several benefits for the industry resulted from this project. The information on the distinct advantage of the $\mathrm{Pt}-\mathrm{RuO} \mathrm{O}_{2}$ electrocatalyst over the Pt-Ru alloy suggests that the IFCC could improve their fuel cells by switching over to the $\mathrm{Pt}^{-\mathrm{RuO}_{2}}$ system. A characterization of the IFCC electrocatalyst by EXAFS and XANES techniques provides useful information for comparison with other systems and evaluation of the electrocatalysts performance. The results on the new Pt-metal oxide electrocatalysts obtained in this project may be a starting point for further work on these promising systems.

\section{Laboratory Benefits}

A new direction in fuel cell electrocatalysis has been established and promising results were obtained. The hardware for the work with high surface area electrodes has been developed. In situ FTIR spectroscopy has been implemented and diffuse reflectance technique for a high surface area systems became available. One patent is currently under evaluation. Further understanding of the principles of methanol oxidation has been achieved. The results from this research could help future fuel cells, batteries and carbon dioxide reduction projects in the Laboratory.

\section{Recommended Follow-on Work and its Potential Benefits}

Further work should focus on finding a method to reduce the particle size of $\mathrm{Ni}$ and Co-tungstates. A success could lead to further optimization of the electrocatalyst, leading to its higher activity. Mixed oxides and several other_promisine oxide materials 
should be investigated as a support for $\mathrm{Pt}$. This work would provide a more complete assessment of the possibilities and intrinsic activities of Pt-metal oxide electrocatalysts.

Publications resulted from this project thus far:

1. N.S.Marinkovic, J.S.Marinkovic and R.R.Adzic, "In situ Infrared Spectroscopic Investigations of Sulfate Adsorption at $\mathrm{Ag}(111)$ Electrodes", J.Electroanal.Chem., in press.

2. N.S.Marinkovic, J.X.Wang, J.S.Marinkovic and R.R.Adzic, "Unusual Adsorption Characteristics of Silver Adlayers on Pt(111) Electrode", J.Phys.Chem., in press.

3. N.S.Marinkovic, J.X.Wang and R.R.Adzic, "In situ Spectroelectrochemical Investigation of $\mathrm{CO}$ Adsorption on Underpotentially Deposited Silver on $\mathrm{Pt}(111)$ Electrode", abstract No.1010, $193^{\text {rd }}$ Meeting of the Electrochemical Society, San Diego, California, May 3-8, 1998.

4. R.R.Adzic and N.S.Marinkovic, "Bifunctional Electrocatalyst for Methanol Oxidation in Fuel Cells", patent pending.

5. S.Mukerjee, J.McBreen, N.S.Marinkovic and R.R.Adzic, "Comparative In Situ X-ray Absorption Studies of Pt-Ru and Pt-RuO 2 Electrocatalysts", in preparation.

6. N.S.Marinkovic and R.R.Adzic, "Methanol Oxidation on $\mathrm{Pt} / \mathrm{NiWO}_{4}$ and $\mathrm{Pt} / \mathrm{CoWO}$ Electrocatalysts", in preparation.

7. N.S.Marinkovic and R.R.Adzic, "In situ Spectroelectrochemical Investigation of Bisulfate and CO Adsorption on Ru(0001)", to be presented on $195^{\text {th }}$ Meeting of the Electrochemical Society, Seatle, WA, May 2-7, 1999. 


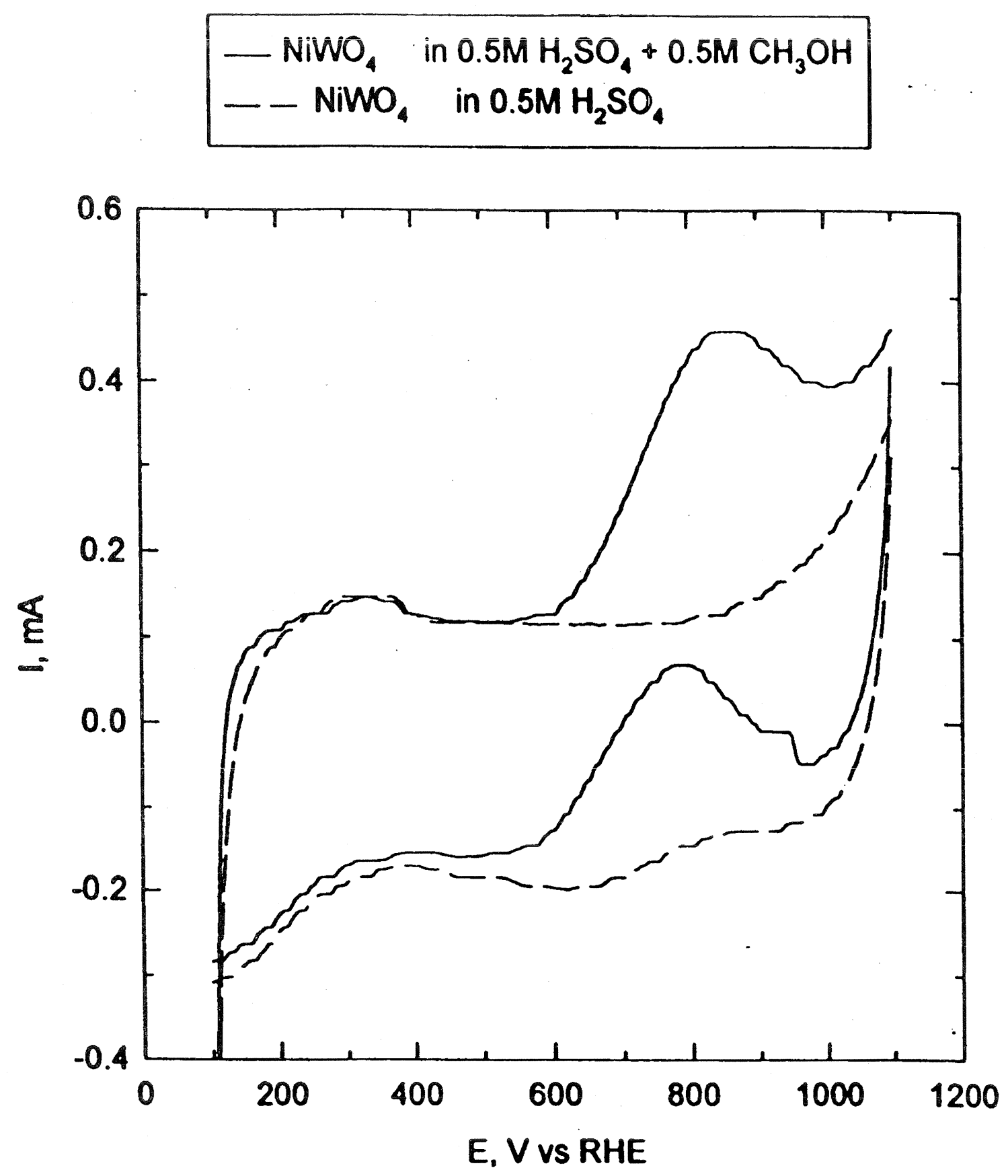




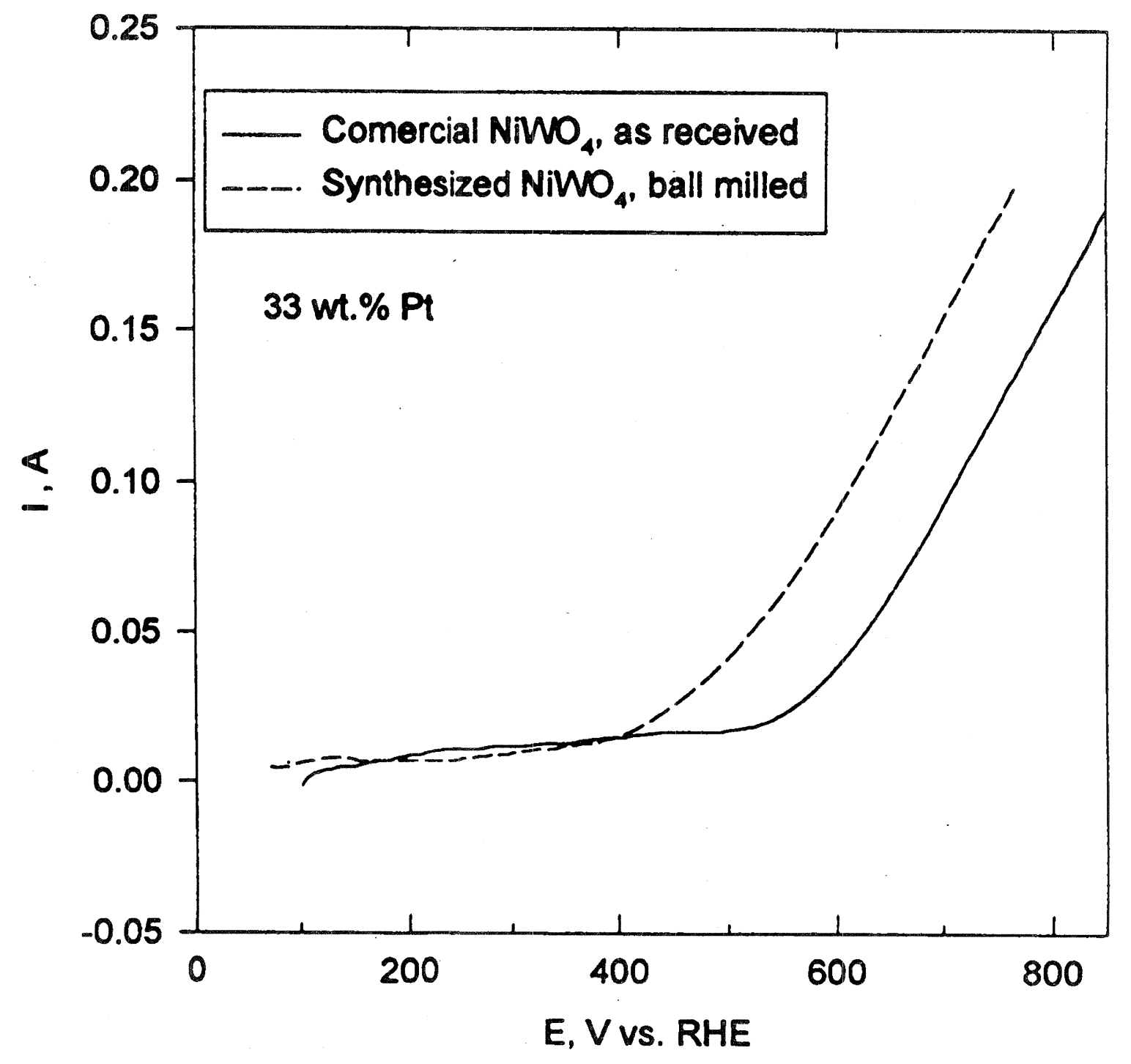




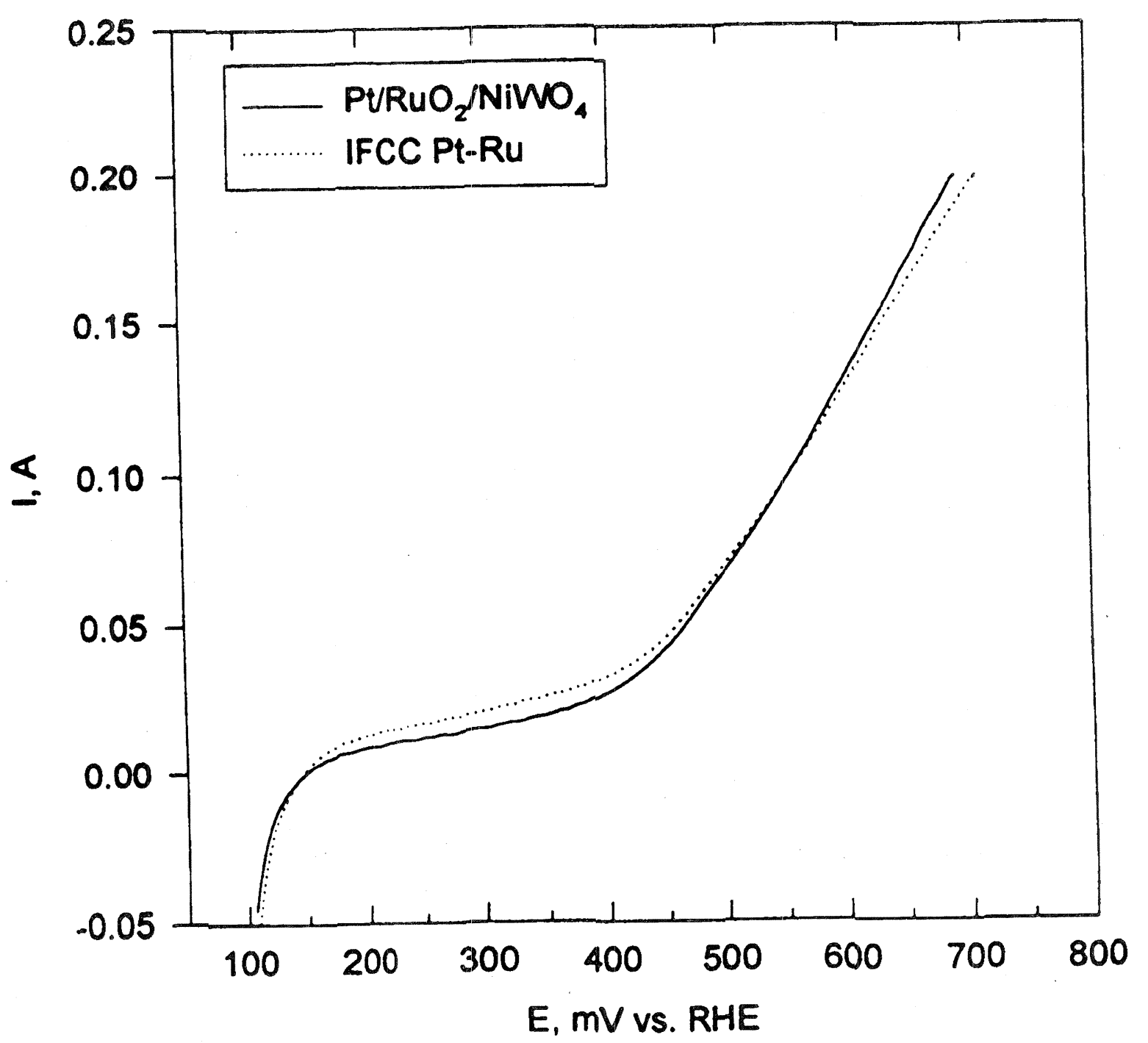




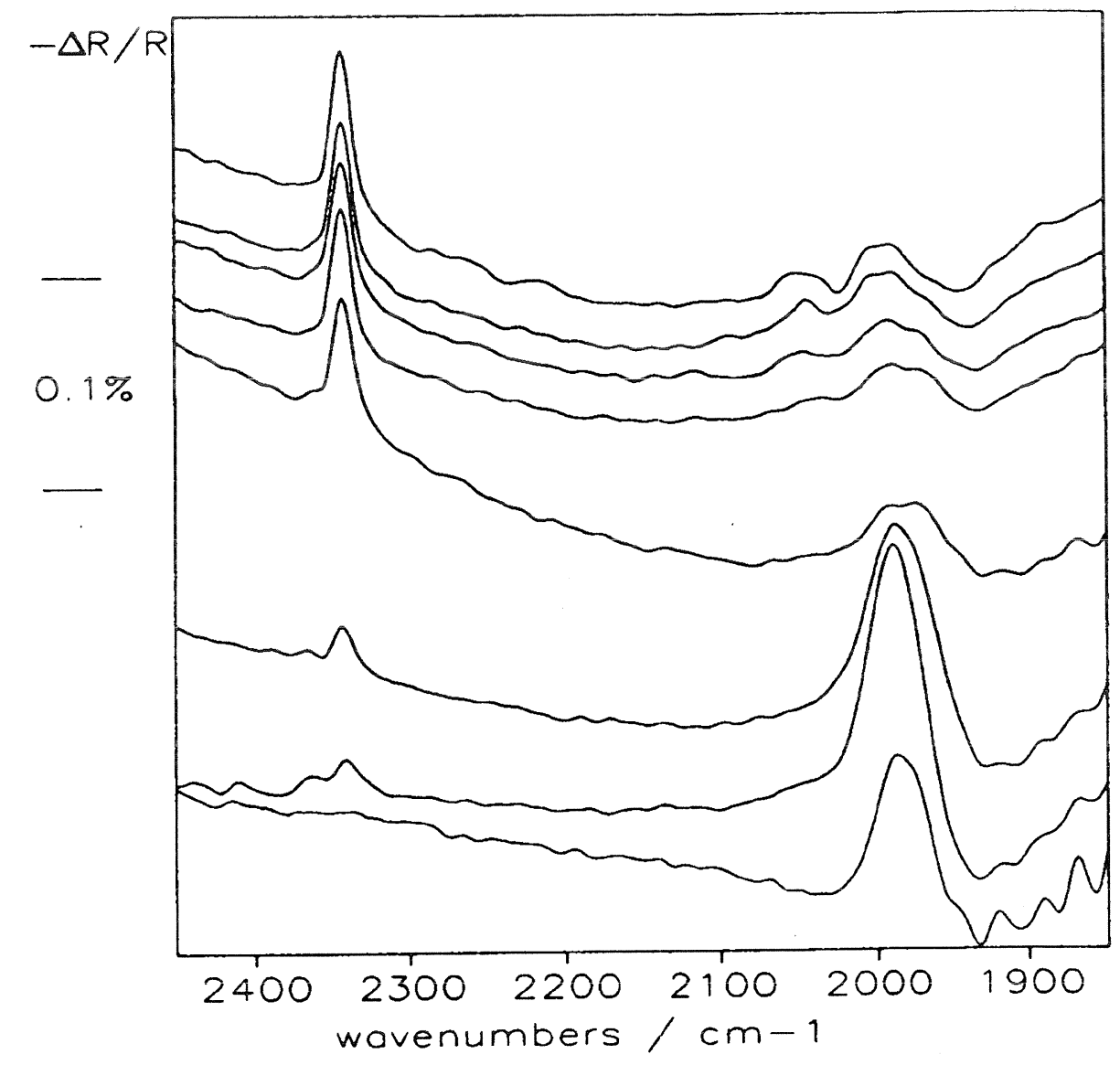

a)

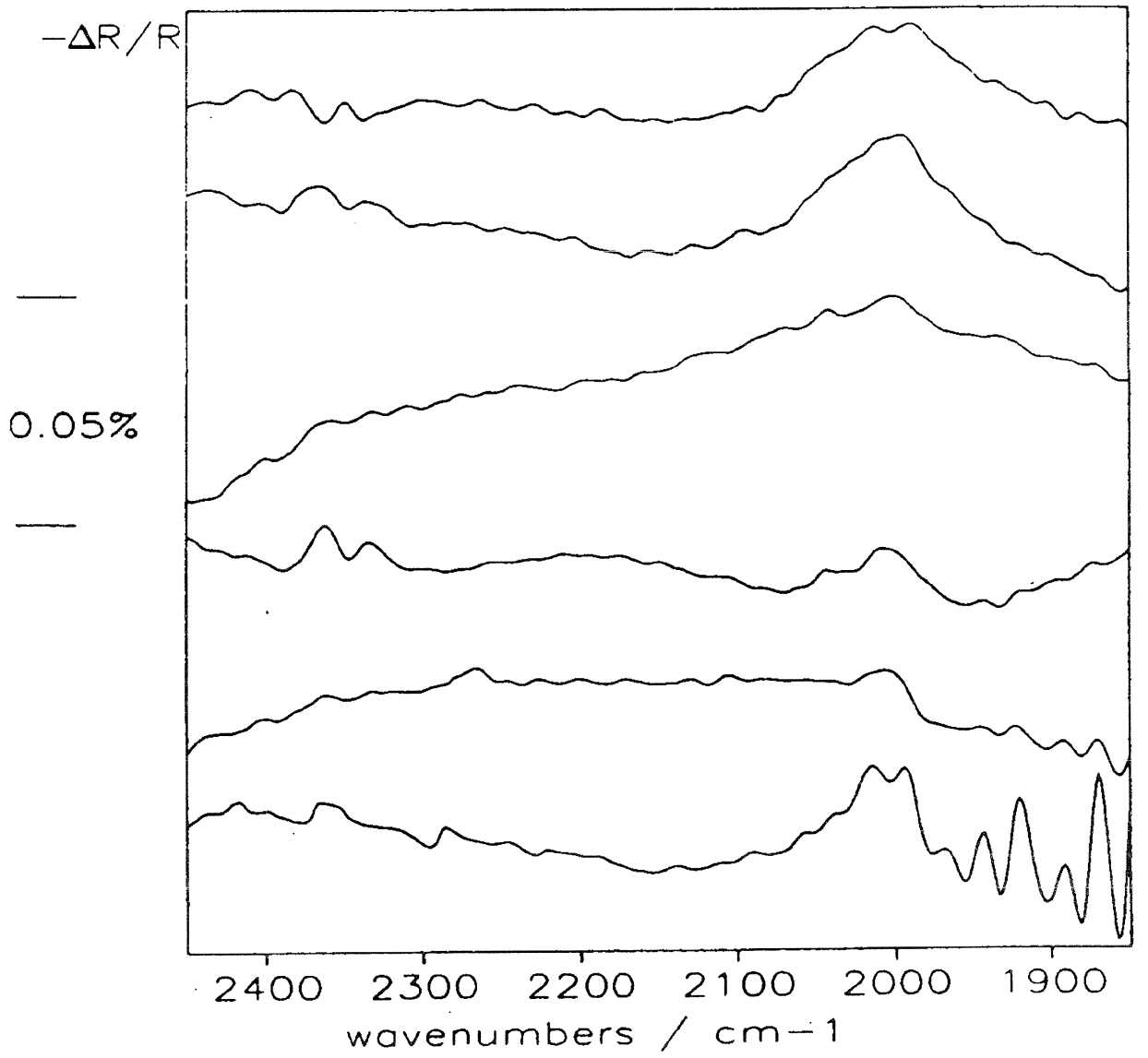

b) 
In situ XANES for PIRU/C in IN NClO, $0.3 \mathrm{NASOOH}$ al the Ru Kedge

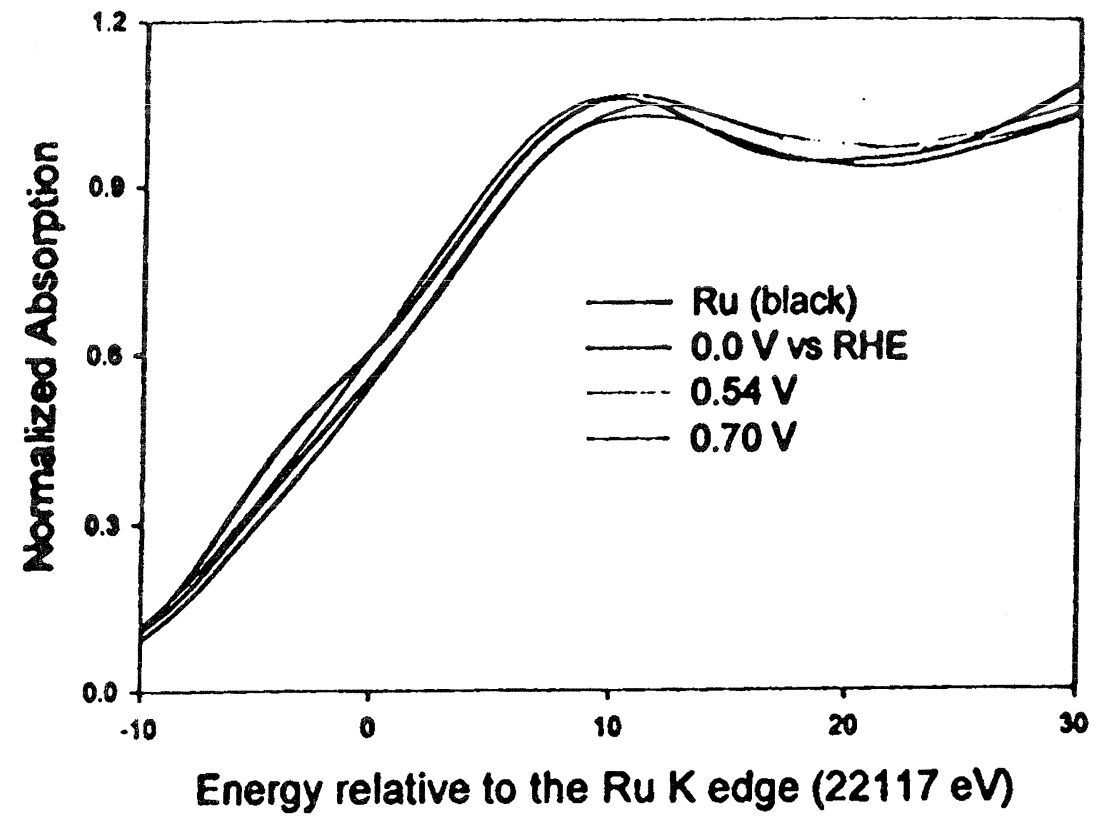

In situ XANES at the $\mathrm{Ru} \mathrm{K}$ edge for $\mathrm{Pt}+\mathrm{RuO}_{2}$ sample in $1 \mathrm{~N} \mathrm{HClO}_{4}+0.3 \mathrm{~N} \mathrm{MeOH}$

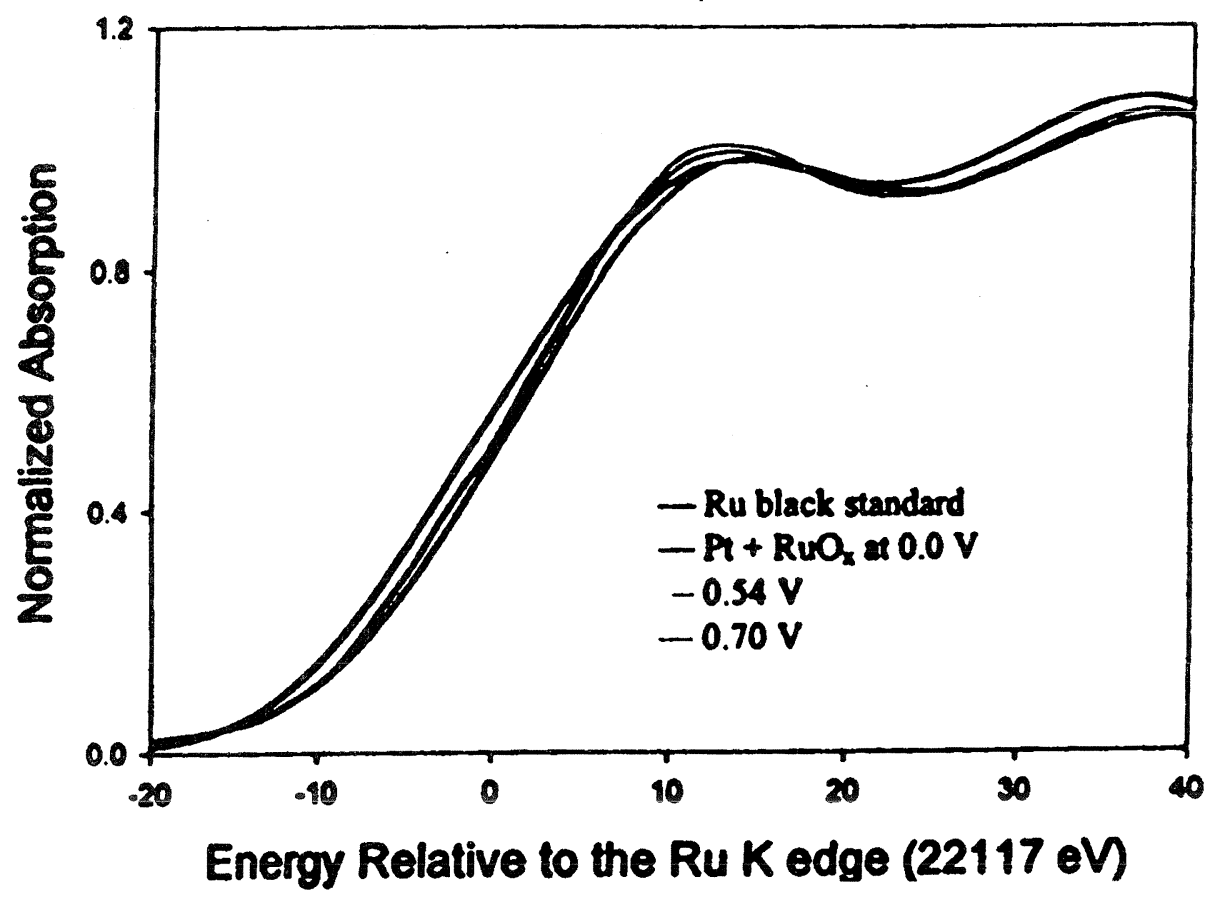




\section{Appendix}

Publications and manuscripts resulted thus far from this project. 


\title{
In situ Infrared Spectroscopic Investigations of Sulfate Adsorption at the $\mathbf{A g}(111)$ Electrode Surface
}

\author{
N. S. Marinković, J. S. Marinković and R. R. Adžić \\ Department of Applied Science, Brookhaven National Laboratory, Upton, NY 11973 and \\ ${ }^{\star}$ Department of Chemistry, University of California, Davis, CA 95616
}

\section{Abstract}

Cyclic voltammetry and in situ infrared spectroelectrochemistry were employed to study the ionic adsorption on the $\mathrm{Ag}(111)$ electrode surface in sulfate-containing solutions of different $\mathrm{pH}$. It has been concluded that the sulfate anion is the predominant species adsorbed at the electrode surface in acidic and neutral medium. The adsorption of sulfate in alkaline solutions is inhibited by more strongly specifically adsorbed $\mathrm{OH}^{-}$ions. The potential dependence of surface coverage, estimated on the basis of spectroelectrochemical data, indicates that a considerable repulsion exists among the adsorbed sulfate species. The spectral data were compared to that obtained for sulfate adsorption on $\mathrm{Pt}(111)$ and on underpotentially deposited $\mathrm{Ag}$ on the $\mathrm{Pt}(111)$ surface.

Keywords: FTIR spectroscopy; Adsorption; Sulfate; Silver(111) electrode

\footnotetext{
- Dedicated to Jean Clavilier on the occasion of his retirement from LEI CNRS and in recognition of his contribution to Interfacial Electrochemistry.
} 


\section{Introduction}

Anion adsorption process on solid electrodes has been a topic of numerous investigations, mainly because it profoundly affects the kinetics of many electrochemical reactions. Recently, a number of in situ techniques has been utilized to study anion adsorption processes [1]. These studies include anion adsorption on Pt $[2,3,4,5,6,7,8,9]$ and $\mathrm{Au}[10,11,12,13,14,15,16]$, using chronocoulometry $[2,13]$, Fourier transform infrared (FTIR) [3-5,7,8,10-12], x-ray scattering $[6,14,16]$, scanning tunneling microscopy (STM) $[9,12]$, and radiotracer measurements [13], as well as surface enhanced Raman scattering (SERS) $[17,18]$. Unlike in the case of these two metals, adsorption data obtained by in situ techniques for silver electrodes are scarce.

In addition to extensive capacitance studies [19], radiotracer measurements conducted on polycrystalline $[20,21]$ and, very recently, on single crystal surfaces [22] of silver provided quantitative information on a number of ions adsorbed, while STM [23] and $\mathrm{x}$-ray scattering [16] furnished the structural information on the halide adlayer on $\mathrm{Ag}(111)$. The latter technique has been also utilized to study the water distribution at $\mathrm{Ag}(111) /$ electrolyte interface [24]. A recent visible-infrared sum-frequency generation (SFG) study provided a first determination of potential of zero charge of silver in $\mathrm{CN}$ containing $\mathrm{NaClO}_{4}$ solution [25].

While all the above in situ techniques provide advantageous information on the structure of the metal/solution interface, only vibrational techniques, SERS and infrared- 
based sechinies, FTIR, SFG and second harmonic generation [26], can identify the type of the ion adsorbed. However, the inherent nature of the SIERS teclmique, where a significant enhancement is achieved only after extensive roughening of the substrate, precludes the studies of well ordered single crystal surfaces. The aim of this work is to utilize the in situ FTIR spectroscopy to identify the nature of ions adsorbed on $\mathrm{Ag}(111)$ The data of sulfate and bisulfate adsorption at the $\mathrm{Ag}(111)$ electrode surface in three solutions of different $\mathrm{pH}$ presented here are compared to that of sulfate/bisulfate adsorption on $\mathrm{Pt}(111)$ and underpotentially deposited (UPD) silver on $\mathrm{Pt}(111)$ substrate $[27,28]$.

\section{Experimental}

Silver single crystal electrode of $0.8 \mathrm{~mm}$ in diameter, obtained from Metal Crystals and Oxides, Cambridge Ltd. was oriented and cut to better than $0.5^{\circ}$, and mechanically polished with alumina and diamond pastes. Before each experimental run the crystal was polished by a procedure similar to the one described in Refs. [22] and [29], using a solution containing $50 \mathrm{ml}$ of a $4 \mathrm{M} \mathrm{CrO}_{3}$ solution and $50 \mathrm{ml}$ of a $0.6 \mathrm{M} \mathrm{HCl}$.

Reversible hydrogen electrodes (RHE) were used as the reference electrodes in acidic and neutral solutions, while $\mathrm{Hg} / \mathrm{HgO}, 0.01 \mathrm{M} \mathrm{OH}$ served as the reference in alkaline medium. All reference electrodes were calibrated against a $\mathrm{Ag} / \mathrm{AgCl}, 3 \mathrm{M} \mathrm{KCl}$ electrode before and after each experiment. The electrode potentials throughout the text are given against this electrode. All chemicals were of the highest purity and used without 
further purification. $\mathrm{NaOH}$ solutions were made from $50 \% \mathrm{w} / \mathrm{w}$ solution (Fisher) to eliminate possible carbonate contaminants. All solutions were made using MilliQ UV-plus water.

The in situ spectroelectrochemical measurements were conducted in a custommade cell, described previously $[7,30]$. In this work, the $\mathrm{CaF}_{2}$ hemispherical window was used and the optical path was modified accordingly. $90^{\circ}$ off-axis mirrors, used in the external chamber of the Mattson RS- 10000 to focus the IR light at the sample, were angled by $14^{\circ}$ with respect to the horizontal plane so that the IR light was directed upward. The IR beam was focused at the $\mathrm{CaF}_{2}$ /solution interface and the incidence angle was set to $76^{\circ}$ (Fig. 1). After the reflection from the interface, the IR light was collimated by a mirror and directed to the MCT detector. The spectrometer and a PAR 273 potentiostat were computer controlled using a program designed to set the potential of the working electrode alternatively to the sample or the reference potential for the working electrode prior to sample acquisition. The reference potential was constant and chosen to be near the onset of the hydrogen evolution in the supporting electrolyte. 4096 scans were coadded in cycles of 128 scans each; the resolution was $8 \mathrm{~cm}^{-1}$. Spectra are given in the form of $-\Delta R / R$, with the positive-going bands representing a gain of a particular species at the sample potential relative to that at the reference.

The angle of incidence at $76^{\circ}$ allows one to obtain information on the metaladsorbate structure in a wide frequency range. Assuming that the refractive index of a dilute aqueous solution is close to that of water, one can draw a critical angle - frequency plot, Fig. 2. It is obvious that at the angle of incidence set to $76^{\circ}$, one obtains information in the whole frequency range from the cutoff of $\mathrm{CaF}_{2}$ window $\left(-1050 \mathrm{~cm}^{-1}\right)$ to better than 
$4000 \mathrm{~cm}^{-1}$, with the exception of the regions where the refractive index of water becomes higher than that of the window, i.e. $1540-1620$ and $2600 \sim 3340 \mathrm{~cm}^{-1}$. The up-looking design of the spectroelectrochemical cell allows one for a quick check of the quality of the single crystal surfaces by recording voltammetry curves before and after the data collection.

\section{Results and Discussion}

\subsection{Cyclic voliammetry}

In order to explain the results obtained by SNIFTIRS in different media (vide infra), voltammograms of the $\mathrm{Ag}(111)$ in the corresponding solutions were recorded. Fig. 3 a shows the voltammetry profile of the $\mathrm{Ag}(111)$ electrode in $0.01 \mathrm{M} \mathrm{NaOH}$. The shape of the voltammogram resembles that presented by Jovic et al. [31] for neutral solutions, and differs from those of Savinova et al [32] and Droog [33] obtained in alkaline media. A characteristic "butterfly"-shaped peak is observed in the region -0.7 to $-0.4 \mathrm{~V}$. The curve in fact has the mirror-image similar to the famous Clavilier's butterfly [34] for hydrogen and bisulfate adsorption on $\mathrm{Pt}(111)$ in $\mathrm{H}_{2} \mathrm{SO}_{4}$ solutions.

In the recent work by Savinova et al. an overview of the carlier results and the assignments for the voltammetric features by different authors, involving hydrogen adsorption, underpotential deposition of $\mathrm{Na}^{+}$and chemisorption of hydroxide species have been reported [32]. However, correlating the peak to UPD of hydrogen is unlikely for 
silver of any orientation, and the underpotential deposition of sodium cations in aqueous solution cannot be observed. Therefore, we conclude that the observed process should be correlated to the adsorption of hydroxide species with a considerable charge transfer, in agreement with the assignments by Savinova et al. [32]. The small spike at $-0.7 \mathrm{~V}$ probably represents some structural rearrangement of $\mathrm{OH}^{-}$ions adsorbed on the $\mathrm{Ag}(111)$ surface. The adsorption process does not end at $-0.4 \mathrm{~V}$, as in the case of sulfate in neutral solution (Fig.3b), but continues with a similar charge transfer over a wide potential region up to $-0.1 \mathrm{~V}$. A well defined peak is noticed in the voltammogram at the potentials positive of $-0.1 \mathrm{~V}$. It probably corresponds to further oxidation of adsorbate which may lead to a formation of more discharged $\mathrm{Ag}-\mathrm{OH}$ or $\mathrm{Ag}-\mathrm{O}$. At $0.1 \mathrm{~V}$ a sharp spike is observed, indicating another structural arrangement of the ordered adsorbate. This is an unusual behavior for $\mathrm{M}-\mathrm{OH}$ or $\mathrm{M}-\mathrm{O}$ adsorbates which contrasts the behavior of disordered $\mathrm{AuOH}$ adlayer [35]. At more positive potentials the usually observed formation of $\mathrm{Ag}_{2} \mathrm{O}$ is observed. When the potential is reversed, the same voltammetric features are observed in cathodic scan, i.e., all the processes are reversible.

In order to ascertain that chromate anions from polishing solutions are not affecting the shape of voltammetry curve, $\mathrm{H}_{2}$ evolution was carried out during $1 \mathrm{~min}$ after the initial run was recorded. This procedure did not change the shape of the voltammogram, indicating the absence of adsorbed chromates at the electrode surface after the polishing procedure.

Figure $3 \mathrm{~b}$ shows a set of cyclic voltammograms for the $\mathrm{Ag}(111)$ electrode in solutions of three different $\mathrm{pH}$, viz. $0.05 \mathrm{M} \mathrm{H}_{2} \mathrm{SO}_{4}, 0.1 \mathrm{M} \mathrm{K}_{2} \mathrm{SO}_{4}(\mathrm{pH} \sim 7)$ and $0.1 \mathrm{M} \mathrm{K}_{2} \mathrm{SO}_{4}$ $+0.1 \mathrm{mM} \mathrm{NaOH}$. Except for the curve in the acidic medium, where only the double layer 
capacity charging is observed in the potential range limited by the hydrogen evolution and Ag dissolution on the negative and positive sides, respectively, the voltammogs ams for the neutral and alkaline media show pronounced peaks near the $-0.6 \mathrm{~V}$. Voltammograms similar to the one in Fig. $3 a$ were presented earlier for the $\operatorname{Ag}(111)$ surface in neutral media of different anions [31]. Since the shape of the voltammogram depends somewhat on the nature of the anion in the supporting electrolyte, the authors concluded that the process represents the adsorption of the corresponding anion. However, our results indicate that the voltammetry features observed in neutral media should be correlated to those observed in alkaline solutions. As observed in Fig. 3, the addition of sulfate (up to $0.1 \mathrm{M}$ concentration) into $0.01 \mathrm{M} \mathrm{NaOH}$ does not alter significantly the voltammetric profile. Therefore, the adsorption features in Fig. 3 for the $\mathrm{Ag}(111)$ electrode in neutral and alkaline sulfate solutions probably correspond to the identical processes which occur in the sulfate-free medium. However, sulfate ions affect the onset of $\mathrm{AgOH}$ or $\mathrm{AgO}$ formation in the alkaline medium by shifting it to more positive potentials, indicating a competitive adsorption of the two adsorbates. Similar process should be expected in the neutral medium. Therefore, the sulfate ions appear to be interacting strongly with the electrode surface, i.e., they are not only physisorbed as concluded in a recent Raman study [36]. It appears that the sulfate ions are chemisorbed as our FTIR results given below indicate. The fact that the voltammetry profiles presented in Fig. 3 show no Faradaic processes that could be correlated to sulfate adsorption is probably due to a small charge transfer from the sulfate ions to the surface. 
3.2. SNIFTIRS measurements in $0.05 \mathrm{M} \mathrm{H}_{2 .} \mathrm{SO}_{4}$

Fig. 4 shows SNIFTIR spectra obtained from sulfate adsorption on $\mathrm{Ag}(111)$ in $0.05 \mathrm{M} \mathrm{H}_{2} \mathrm{SO}_{4}$. A distinctive feature of the spectra is a band at $\sim 1170 \mathrm{~cm}^{-1}$ that shifts to the higher wavenumbers as the potential is made more anodic. Similar phenomenon has been reported for the bisulfate adsorption on $\mathrm{Pt}(111)$ in the same electrolyte [37]. A comparison of the spectra for the two metals, as well as for the sulfate adsorption on UPD $\mathrm{Ag} / \mathrm{Pt}(111)$ substrate [27], however, reveals that there is a significant difference in frequencies of the bands. At the bare $\mathrm{Pt}(111)$ electrode and at a monolayer of silver deposited on $\operatorname{Pt}(111)$, the band for the sulfuric acid anions appears at $-1200 \mathrm{~cm}^{-1}$ and shifts to higher wavenumbers as the potential increases in anodic direction. This shift has a rate of $\sim 100$ and $\sim 40 \mathrm{~cm}^{-1} / \mathrm{V}$ for $\mathrm{Pt}(111)$ and monolayer of $\mathrm{Ag}$ on $\mathrm{Pt}(111)$, respectively $[38,27]$. At $\mathrm{Pt}(111)$, this band was ascribed to the strongly blue-shifted $\mathrm{SO}_{3}$ stretch of adsorbed bisulfate on platinum surface, or, more precisely, to the $\mathrm{H}_{3} \mathrm{O}^{-}-\mathrm{SO}_{4}{ }^{2-}$ ion pair. It has also been shown that the band is only seen when the solution $\mathrm{pH}$ is close to, or below the $\mathrm{pKa}$ for the sulfate/bisulfate conversion, i.e. in solutions of $\mathrm{pH}$ lower than 2.0 . It is absent in solutions of higher $\mathrm{pH}$ values [37].

In the $\mathbb{R}$ frequency region above $1000 \mathrm{~cm}^{-1}, \mathrm{HSO}_{4}^{-}$anion in an aqueous solution shows an antisymmetric stretching mode of $\mathrm{SO}_{3}$ at $1195 \mathrm{~cm}^{-1}$, and a totally symmetric stretch at $1040 \mathrm{~cm}^{-1}$. The latter band could not be observed in the present experiments due to proximity to the cutoff of the window used. A single band is observed for a sulfate- 
containing aqueous solution at $1104 \mathrm{~cm}^{-1}$, representing the antisymmetric stretching mode of the $\mathrm{SO}_{4}{ }^{2 \cdot}$ anion [39]

The band at $\sim 1170 \mathrm{~cm}^{-1}$ in Fig. 4, therefore, could be ascribed either to red-shifted $v_{a s}\left(\mathrm{SO}_{3}\right)$ for bisulfate ion, or strongly blue shifted bands for bisulfate and sulfate species. A shift to lower wavenumbers (to the red) physically represents a weakening of the $S=0$ bonds in a bisulfate molecule. Ab-initio calculations show that oxygen lone-pair electron orbitals exhibit anti-bonding character for SO bond in bisulfate and that the donation of these lone-pair electrons to metal surface should cause strengthening of the SO bond [8]. Upon approach of a positively charged species $\left(\mathrm{Li}^{+}\right.$in $\left.[8]\right)$, the authors showed that the $v_{8}\left(\mathrm{SO}_{3}\right)$ mode shifts to higher, and the $v_{2 s}\left(\mathrm{SO}_{3}\right)$ mode to lower frequencies. With increasing positive charge of the approaching species, however, the $v_{2 s}\left(\mathrm{SO}_{3}\right)$ mode should be moved further to the red. In the present case, the band at $\sim 1170 \mathrm{~cm}^{-1}$ in Fig. 4 moves to higher frequencies as the potential is made more positive. Therefore, ascribing the band at $\sim 1170 \mathrm{~cm}^{-1}$ to the $v_{2 s}\left(\mathrm{SO}_{3}\right)$ mode of bisulfate would be difficult to justify.

In order to find the further information on the predominant species adsorbed on the metal surface, the study has been conducted in the solutions of different $\mathrm{pH}$ values. As it will be presented below, the band at $\sim 1170 \mathrm{~cm}^{-1}$ appears in acidic solutions of $\mathrm{pH}$ both below and above the second dissociation constant of sulfuric acid $\left(\mathrm{pK}_{\mathrm{a}}=1.93\right)$. Since the concentration of bisulfate ions in a neutral solution is negligible, the band is ascribed to the strongly shifted $v\left(\mathrm{SO}_{4}{ }^{2-}\right)$ mode of sulfate. This judgment is also supported by the data of Shi et al. who, on the basis of chronocoulometric and radiotracer measurements, concluded that sulfate is the predominant species adsorbed on Au, another metal of similar electronic structure, even at low $\mathrm{pH}$ values [10]. Furthermore, a Raman study of 
polycrystalline silver in $1 \mathrm{M} \mathrm{H}_{2} \mathrm{SO}_{4}$ shows no signs of the bands for the adsorbed $\mathrm{HSO}_{4}{ }^{-}$ ions [40]. A broad band at $1165 \mathrm{~cm}^{-1}$ observed in that study was correlated to sulfate adsorbed on the $\mathrm{Ag}$ electrode. On the other hand, the conclusion on the predominant sulfate adsorption on $\mathrm{Ag}(111)$ is in apparent disagreement with that of Horanyi et al. [20] The authors concluded that bisulfate should be the predominant adsorbed species at a polycrystalline silver electrode, although it has been acknowledged that the strong electric field in the double layer near the silver electrode may facilitate the dissociation of bisulfate ions therein $[20,21]$.

The potential dependency of the integrated area of the electrode for two separate runs is given in Fig. 5a. It is calculated as the area under the baseline-corrected band in the region $v_{p}+25 \mathrm{~cm}^{-1}$, where $v_{p}$ is the peak frequency, and normalized with the instrument throughput factor for each experimental run. This factor is considered to be constant within an experiment, and represents the figure of merit for the IR spectroelectrochemical experiment, as discussed in Ref. [7]. The pseudo-isotherms given in Figure 5a are consistent with electrochemical and radiotracer investigations of bisulfate-anion adsorption on $\mathrm{Ag}$ [19-22]. The amount of anion adsorbed on the metal surface monotonically increases up to $0.2 \mathrm{~V}$. However, as the potential is further increased, it seems that the anion coverage reaches a saturation indicated by a plateau above $0.25 \mathrm{~V}$.

The pseudo-isotherm in Fig. 5a with a linear dependence of coverage in a relatively wide potential region indicates a Temkin adsorption behavior, i.e. a repulsive interaction among sulfate anions at the $\mathrm{Ag}(111)$ electrode. The repulsive interaction is in agreement with the results of Smolinski et al. [22] who found that the Frumkin adsorption behavior with repulsion between adsorbate species for $\mathrm{Ag}(111)$ and that only $34 \%$ of the electrode 
surface is covered with sulfate. However, our voltammetry curves (vide supra) together with the FIIR results presented in the next section indicate that the sulfate coverage could be even smaller

Figure $5 b$ shows the peak frequency of the adsorbed sulfate band as a function of the applied potential. A linear dependence is oblained in the wide range of the potential, with a slope of about $60 \mathrm{~cm}^{-1} / \mathrm{V}$. A close observation of the Fig. $5 \mathrm{~b}$ shows that the slope can be as high as $110 \mathrm{~cm}^{-1} / \mathrm{V}$ in the potential range up to about $0.1 \mathrm{~V}$ vs. $\mathrm{Ag} / \mathrm{AgCl}$. A comparison of the data presented in Figs. $5 \mathrm{a}$ and $5 \mathrm{~b}$ reveals that the slope may depend on the coverage of the sulfate at the surface, as discussed in the next paragraph.

The frequency shift with potential of the species adsorbed on electrode surfaces can be explained in terms of one or more of the following mechanisms: electron donation between the adsorbate and the metal surface (vibronic coupling), coupling of the electric field that exist in the double layer with the dipole moment of the adsorbates (Stark effect), and interaction from dipole-dipole coupling due to coverage increase $[41,42]$. It is possible that the last mechanism lowers the $v_{p}(E)$ slope in Fig. $5 b$ at the higher coverages. Furthermore, the large interactive parameter for sulfate at $\mathrm{Ag}(111)$ [22] indicates a small charge transfer from the adsorbed sulfate ions to the electrode surface, in the agreement with the shape of the cyclic voltammograms in Fig.3, where no process other than the double layer charging is observed. Consequently, a large repulsion exist among the partially negative-charged adsorbates, which could cause the lowering of the peak frequency plot with the potential in Fig. $5 b$. 


\subsection{SNIFTIRS measurements in O. IM K 2.5 .}

Fig. 6 shows SNIFTIRS spectra of anion adsorption on the $\mathrm{Ag}(111)$ surface in $0.1 \mathrm{M} \mathrm{K}_{2} \mathrm{SO}_{4}$. As in the previous section, a strong, positive going band at $\sim 1160 \mathrm{~cm}^{-1}$ is observed. The peak maximum of the band steadily shifts to higher wavenumbers as the potential is made more positive. Since the concentration of bisulfate ions is negligible in the neutral solution, the band is associated with the adsorption of sulfate species at the silver surface.

The reference spectrum for the spectra presented in Fig. 6 is taken at $-0.48 \mathrm{~V}$, i.e. in the range of $\mathrm{AgOH}$ formation. As can be inferred from the voltammogram in Fig. 3, the $\mathrm{AgOH}$ formation proceeds all the way to about $-0.2 \mathrm{~V}$. On the other hand, since the SNIFTIRS bands become visible in spectra above $-0.33 \mathrm{~V}$, one concludes that $\mathrm{SO}_{4}{ }^{2-}$ ions adsorb at the surface partially occupied by hydroxyl anions.

The SNIFITRS band corresponding to the sulfate adsorption at $1160 \mathrm{~cm}^{-1}$ increase in intensity up to about $0.02 \mathrm{~V}$. As seen from the Fig. 6 , the three topmost spectra taken at potentials of 0.02 and above have practically identical intensity. This behavior can be seen more clearly in the Fig. 7a, where the integrated band intensities for two separate runs are plotted as a function of potential of the $\mathrm{Ag}(111)$ electrode. The $A_{i}(E)$ plot in Fig. 7a shows that a plateau is reached above $0.02 \mathrm{~V}$.

Fig. $7 \mathrm{~b}$ shows the frequency change of the band for adsorbed sulfate with potential in $0.1 \mathrm{M} \mathrm{K}_{2} \mathrm{SO}_{4}$. A potential shift of the band maximum with a rate of $40 \mathrm{~cm}^{-1} / \mathrm{V}$ is observed in the entire potential region. Such a relatively small shift, as well as the absence 
of the change in the $v_{\mathrm{p}}$ (E) plot, as opposed to those observed in the acidic medium indicate that adsorption processes take place in different chemical environment in the two solutions. The most probable reason for this is the competition for sites between adsorbed $\mathrm{OH}$ and $\mathrm{SO}_{4}{ }^{2-}$ ions in the neutral medium. The sulfate adsorption in the acidic solution proceeds on the silver electrode free of anions, whereas that in the neutral medium advances on an electrode partially occupied by hydroxyl groups. From the differences in sulfate concentration in acidic and neutral media one could expect that the SNIFTIR spectra taken in the neutral solution should have higher intensity. The differences in the chemical environment, which lead to a different surface state, make the sulfate bands in the neutral solution to be less intense.

\subsection{SNIFTIRS measurements in $0.5 \mathrm{M} \mathrm{H}_{2} \mathrm{SO}_{4}$ and in $0.1 \mathrm{M} \mathrm{K}_{2} \mathrm{SO}_{4}+0.01 \mathrm{M} \mathrm{NaOH}$}

Spectra for the sulfate adsorption in the highly concentrated sulfuric acid solution are given in Fig. 8 . The sulfate band at $-1170 \mathrm{~cm}^{-1}$ is observed again, as in the two previous solutions discussed above, but with a much smaller intensity. In fact, the band could be distinguished from the background noise only in the spectra taken at the most positive potentials. This is not surprising, since in this solution the sulfate concentration is about 40 times smaller than that of bisulfate.

It has been assumed that a strong electric field near the polycrystalline silver electrode may facilitate the conversion of bisulfate into sulfate ions $[20,21]$. If such a process is operative in the case of the $\mathrm{Ag}(111) / 0.5 \mathrm{M} \mathrm{H}_{2} \mathrm{SO}_{4}$ system, the loss of bisulfate 
in the double layer should be observed in a SNIFTIR spectrum as a negative-going band centered at $-1200 \mathrm{~cm}^{-1}$, which gains in intensity as the potential is made more positive. No such band is seen in Fig. 8 . Consequently, the intensity of the sulfate band at $\sim 1170 \mathrm{~cm}^{-1}$ is governed solely by the bulk concentration of sulfate in this solution. If one assumes a negligible ion diffusion from the bulk of the solution into the solution gap betwcen the electrode and the window, and the gap thickness of $1 \mu \mathrm{m}$, one obtains the maximum surface coverage of sulfate to be about $\theta=0.30$, taking the nearest neighbor separation for silver of $0.2889 \mathrm{~nm}$ [43] and the bulk $\mathrm{SO}_{4}{ }^{2-}$ concentration of $12 \mathrm{mM}$. This value is close to the maximum coverage of sulfate at $\mathrm{Ag}(111)$ calculated on the basis of radiotracer measurements [22]. The intensity of the bands in Fig. 8 is, however, too small for such a large coverage of $\mathrm{SO}_{4}{ }^{2-}$. The sulfate coverage of $\theta=0.3$ is close to a completely covered Ag(111) surface with ions adsorbed on three-fold symmetry sites. Such adsorption requires a considerable charge transfer which would produce a small peak in voltammetry curve, similar to that at $\mathrm{Pt}(111)$. This is not observed for $\mathrm{Ag}(111)$, see Fig.3. Therefore the FTIR and voltammetry data indicate that the sulfate coverage on $\mathrm{Ag}(111)$ is small.

From the three topmost spectra in Fig. 8 one can estimate the rate of the shift of the sulfate adsorption band with the potential to be about $50 \mathrm{~cm}^{-1} / \mathrm{V}$. However, due to low intensity of the bands, the plots of $v_{p}(E)$ and $A_{i}(E)$ are not given here.

In the solution of $0.1 \mathrm{M} \mathrm{K}_{2} \mathrm{SO}_{4}+0.01 \mathrm{M} \mathrm{NaOH}$ the sulfate bands in the SNIFTIR spectra could not be distinguished from the background. We therefore conclude that the $\mathrm{OH}$ ions, which are known to be more specifically adsorbed than sulfate, preclude the adsorption of $\mathrm{SO}_{4}{ }^{2 \cdot}$. From the voltammogram in Fig. 3 one observes that the adsorption of hydroxyl ions and formation of $\mathrm{AgOH}$ proceeds all the way to the onset of silver 
oxidation. The fractional coverage of hydroxyl groups incrcases with the potential, leaving less free sites for the sulfate adsorption. This is different from the behavior in the neutral solution where in the potential region between -0.2 and $0.2 \mathrm{~V}$ no process other than the double layer charging is observed in the voltammogram so that the sulfate adsorption can proceed on the sites free of $\mathrm{OH}^{-}$ions.

\section{General Discussion and Conclusions}

The adsorption of sulfuric acid anions on $\mathrm{Ag}(111)$ is interesting to compare with adsorption on Ag monolayer and bilayer on the $\mathrm{Pt}(111)$ electrode surface. A comparison of the spectra for these three surfaces reveals significant differences in adsorption properties. It has been found that the bisulfate ions strongly adsorb on the $\operatorname{Pt}(111)$ surface $[37,38]$, while sulfate species are predominantly adsorbed on $\mathrm{Ag}(111)$ surface, as shown in the present work. On the $\mathrm{Ag}$ monolayer on $\mathrm{Pt}(111)$, however, the adsorption of bisulfate is observed [27]. This indicates that $\mathrm{Pt}$ strongly affects the electronic properties of $\mathrm{Ag}$ monolayer. Adsorption of $\mathrm{CO}$ on this surface [44], but not on $\mathrm{Ag}(111)$, corroborates the above view, as well as redistribution of charges in 5d-and 4d-orbitals of $\mathrm{Pt}$ and $\mathrm{Ag}$ observed at metal-gas interface [45]. On the Ag bilayer on Pt(111), adsorption of sulfate is observed [27] as on the bulk $\mathrm{Ag}(111)$, indicating that already the $\mathrm{Ag}$ bilayer on $\mathrm{Pt}(111)$ acquires some of the bulk $\mathrm{Ag}$ properties. These data suggest an interesting correlation between the adsorption behavior and the chemical nature of the metal surface. It appears that the (111) oriented surfaces of sp-metals, like $\mathrm{Ag}$ and $\mathrm{Au}$ [13], predominantly adsorb 
sulfate anions, whereas a d-metal Pt adsorb bisulfate. It remains to be seen whether this conclusion can be applied to other d-metals.

In summary, the data obtained by in situ spectroelectrochemistry presented above demonstrate specific adsorption of sulfate anions on the $\mathrm{Ag}(111)$ electrode surface. Pseudo-isotherms obtained from IR data show a large lateral repulsion between adsorbed sulfate anions indicating a small charge transfer in this system. Voltammetric and FTIR data indicate that the strong specific adsorption of hydroxyl anions on $\mathrm{Ag}(111)$ in solutions of higher $\mathrm{pH}$ values inhibit the adsorption of sulfate, eventually completely blocking it in strong alkaline solutions.

\section{Acknowledgments}

This research was performed under the auspices of the US Department of Energy, Division of Chemical Sciences and Materials Sciences Division, under Laboratory Energy Research Program No. DE-AC02-98CH10886. 


\section{References}

[1] Llectrochemical Imerfaces, H.D. Abruña (Ed.), VCH Publishers, New York (1991)

[2] W.Savich, S.G.Sun, J.Lipkowski and A.Wieckowski, J.Electroanal.Chem, 388 (1995) 233.

[3] C.S.Kim and C.Korzeniewski, J.Phys.Chem., 97 (1993) 9784

[4] E.Pastor, A.Rodes and T.Iwasita, J.Electroanal.Chem., 404 (1996) 61.

[5] K.Ashley, D.L.Feldheim, D.B.Parry, M.G.Samant and M.R.Philpott, J.Electroanal.Chem., 373 (1994) 201.

[6] C.A.Lucas, N.M.Marković and P.N.Ross, Phys.Rev. B, 55 (1997) 7964.

[7] P.W.Faguy and N.S.Marinković, Anal.Chem., 67 (1995) 2791.

[8] Y.Sawatari, J.Inukai and M.Ito, J.Electron Spec.Rel.Phenomena, 64/65 (1993) 515.

[9] A.M.Futnikov, U.Stimming and R.Vogel, J.Electroanal.Chem., 428 (1997) 147.

[10] M.C.P.M.da Cunha, M.Weber and N.C.Nart, J.Electroanal.Chem., 414 (1996) 163.

[11] M.Weber and N.C.Nart, Electrochim.Acta, 41 (1996) 653.

[12] G.Edens, X.Gao and M.J.Weaver, J.Electroanal.Chem., 375 (1994) 357.

[13] Z.Shi, J.Lipkowski, M.Gamboa, P.Zelenay and A.Wieckowski, J.Electroanal.Chem., 366 (1994) 317.

[14] O.M.Magnussen, B.M.Ocko, R.R. Adžić and J.X.Wang, Phys.Rev. B, 51 (1995) 5510 .

[15] J.X.Wang, G.M.Watson and B.M.Ocko, J.Phys.Chem., 100 (1996) 6672.

[16] B.M.Ocko, O.M.Magnussen, J.X.Wang, R.R. Adžić and Th.Wandlowski, Physica B, 221 (1996) 238

[17] M.Fleischmann, P.Graves, 1.Hill, A.Oliver and J.Robinson, J.Electroanal.Chem., 150 (1983) 33

[18] T.Itoh, Y.Sasaki, T.Maeda and C.Horie, Surf.Sci., 389 (1997) 212

[19] A.Hamelin, J.Electroanal.Chem., 145 (1983) 225.

[20] G.Horanyi, E.M.Rizmayer and J.Konya, J.Electroanal Chem., 176 (1984) 339.

[21] P.Zejenay, M.Gamboa-Aldeco, G.Horanyi and A.Wieckowski, J.Electroanal.Chem., 357 (1993) 307.

[22] S.Smolinski, P.Zelenay and J.Sobkowski, J.Electroanal.Chem., 442 (1998) 41.

[23] G.Aloisi, A.M.Futnikov and T.Will, J.Electroanal.Chem., 370 (1994) 297.

[24] M.F.Toney, J.N.Howard, J.Richer, G.L.Borges, J.G.Gordon, O.R.Melroy, D.G.Wiesler, D. Yee and L.B.Sorensen, Surf.Sci., 335 (1995) 326.

[25] A.Tadjeddine, A.Permans and P.Guyot-Sionnest, Surf.Sci., 335 (1995) 210.

[26] F.T.Wagner and P.N.Ross Jr., J.Electroanal.Chem., 150 (1983) 141.

[27] N.S.Marinković, J.S.Marinković and R.R.Adžić, in preparation.

[28] N.S.Marinkovic, J.X.Wang and R.R.Adžic, Proceedings of the Electrochemical Society, Vol.97-17, Pennington, NJ (1997), p.251.

[29] A.Hamelin, L.Doubova, L.Stoicoviciu and S.Trasatti, J.Electroanal.Chem., 244 (1988) 133; T.Kurasawa, Patent, Japan, 35-5619, May 23, 1960.

[30] N.S.Marinković, M.Hecht, J.S.Loring and W.R.Fawcett, Electrochim.Acta, 41 (1996) 641.

[31] V.D.Jović, R.Parsons and B.M.Jović, J.Electroanal.Chem., 339 (1992) 327. 
[32] E.R.Savinova, P.Kraft, B.Pettinger and K Doblhofer, .J.Islectroanal.Chem., 430 (1997) 47.

[33] J.M.M.Droog, J.Lilectroanal.Chem., 115 (1980) 225.

[34] J.Clavilier, R.Faure, G.Guinett and R.Durand, J.Electroanal.Chem., 107 (1980) 205.

[35] C.M.Vitus and A.J.Davenport, J.Electrochem.Soc., 141 (1994) 1291.

[36] L.Rintoul, K.Crawford, H.F.Shurvell and P.M.Fredericks, Vibrational Spectrosc., 15 (1997) 171.

[37] P.W.Faguy, N.S.Marinković and R.R.Adžić, Langmuir, 12 (1996) 243.

[38] P.W.Faguy, N.S.Marinković and R.R.Adžić, J.Electroanal.Chem., 407 (1996) 209.

[39] S.D.Ross, Inorganic Infrared and Raman Spectra, McGraw Hill, London, 1972.

[40] Y.Sasaki and Y.Nishina, Surf.Sci., 242 (1991) 549.

[41] R.M.Hammaker, A.Francis and R.P.Eischens, Spectrochim.Acta, 21 (1965) 1295.

[42] K.Ashley and S.Pons, Chem.Rev., 88 (1988) 673.

[43] J.X.Wang, N.S.Marinković, R.R.Adzić and B.M.Ocko, Surf.Sci.Letters, 398 (1998) L291.

[44] N.S.Marinković, J.X.Wang and R.R. Adžić, 193rd Meeting of Electrochemical Society, San Diego, CA, May 03-08 1998, abstract No.1010.

[45] J.A.Rodriguez and M.Kuhn, J.Phys.Chem., 98 (1994) 11251. 
Figure Captions

Figure 1. The optical path of the spectroelectrochemical cell used in the study. $A, A^{\prime}, 90^{\circ}$ off-axis mirrors; $\mathrm{B}, \mathrm{CaF}_{2}$ hemisphere; $\mathrm{C}$, Teflon cell body; $\mathrm{D}$, Silver electrode; E, Teflon tube; F, Pt wire; G, IR source; and H, MCT detector. The counter electrode ( $\mathrm{Pt}$ wire wound in a loop around the working electrode) and the reference electrode, pushed from a side into the Teflon cell body were omitted from the drawing for clarity.

Figure 2. Critical angle dependency on frequency for the $\mathrm{CaF}_{2} /$ water interface. Dotted line represents the angle of incidence of $76^{\circ}$, used in this study.

Figure 3. Voltammetry curves for the $\mathrm{Ag}(111)$ electrode in $0.01 \mathrm{M} \mathrm{NaOH}$ (a), and in sulfate-containing solutions of different $\mathrm{pH}(\mathrm{b}): 0.05 \mathrm{M} \mathrm{H}_{2} \mathrm{SO}_{4}(\cdot-\cdot-\cdot), 0.1 \mathrm{M}$ $\mathrm{K}_{2} \mathrm{SO}_{4}(\ldots)$ and $0.1 \mathrm{M} \mathrm{K}_{2} \mathrm{SO}_{4}+0.01 \mathrm{M} \mathrm{NaOH}(-)$. Sweep rate 50 $\mathrm{mV} / \mathrm{s}$.

Figure 4. SNIFTIR spectra of sulfate adsorption on $\mathrm{Ag}(111)$ in $0.05 \mathrm{M} \mathrm{H}_{2} \mathrm{SO}_{4} .4096$ scans were coadded in 16 cycles, 256 scans each; the resolution was $8 \mathrm{~cm}^{-1}$. Spectra are collected in the potential range from -0.193 (bottom spectrum) to $0.307 \mathrm{~V}$ vs. $\mathrm{Ag} / \mathrm{AgCl}, 3 \mathrm{M} \mathrm{KCl}$ (top spectrum) in $45 \mathrm{mV}$ increments. Reference spectra obtained at $-0.223 \mathrm{~V}$. Spectra are offset for clarity.

Figure 5. Integrated intensity (a), and peak maxima (b) dependency on potential of the working electrode for two independent measurements of $\mathrm{Ag}(111)$ in $0.05 \mathrm{M}$ $\mathrm{H}_{2} \mathrm{SO}_{4}$, normalized by the throughput factor.

Figure 6. SNIFTIR spectra of sulfate adsorption on $\mathrm{Ag}(111)$ in $0.1 \mathrm{M} \mathrm{K}_{2} \mathrm{SO}_{4}$. Sample spectra are collected in the potential range from -0.38 (bottom spectrum) to $0.12 \mathrm{~V}$ vs. $\mathrm{Ag} / \mathrm{AgCl}, 3 \mathrm{M} \mathrm{KCl}$ (top spectrum) in $50 \mathrm{mV}$ increments. 4096 scans were coadded in 16 cycles, 256 scans each; the resolution was $8 \mathrm{~cm}^{-1}$. Reference spectra obtained at $-0.48 \mathrm{~V}$. Spectra are offset for clarity.

Figure 7. Integrated intensity (a), and peak maxima (b) dependency on potential of the working electrode for two independent measurements of $\mathrm{Ag}(111)$ in $0.1 \mathrm{M}$ $\mathrm{K}_{2} \mathrm{SO}_{4}$, normalized by the throughput factor.

Figure 8. SNIFTIR spectra of sulfate adsorption on $\mathrm{Ag}(111)$ in $0.5 \mathrm{M} \mathrm{H}_{2} \mathrm{SO}_{4}$. Sample spectra are collected in the potential range from -0.125 (bottom spectrum) to $0.275 \mathrm{~V}$ vs. $\mathrm{Ag} / \mathrm{AgCl}, 3 \mathrm{M} \mathrm{KCl}$ (top spectrum) in $50 \mathrm{mV}$ increments. 4096 scans were coadded in 16 cycles, 256 scans each; the resolution was $8 \mathrm{~cm}^{-1}$. Reference spectra obtained at $-0.225 \mathrm{~V}$. Spectra are offset for clarity. 


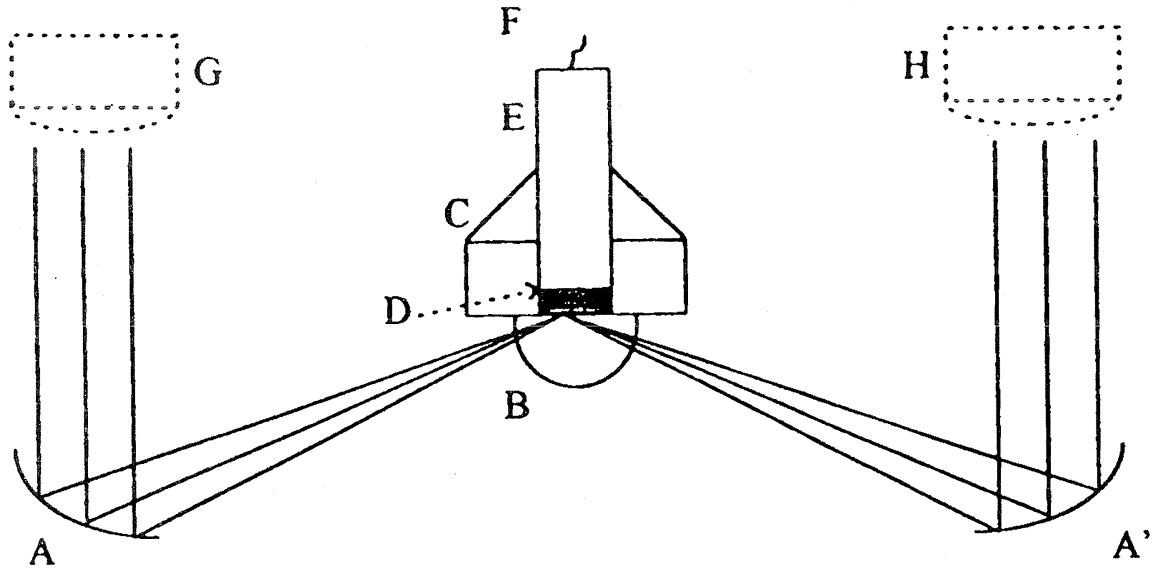

N.S.Marinkovic et al. "In situ Infrared Spectroscopic Investigations...", Figure 1. 


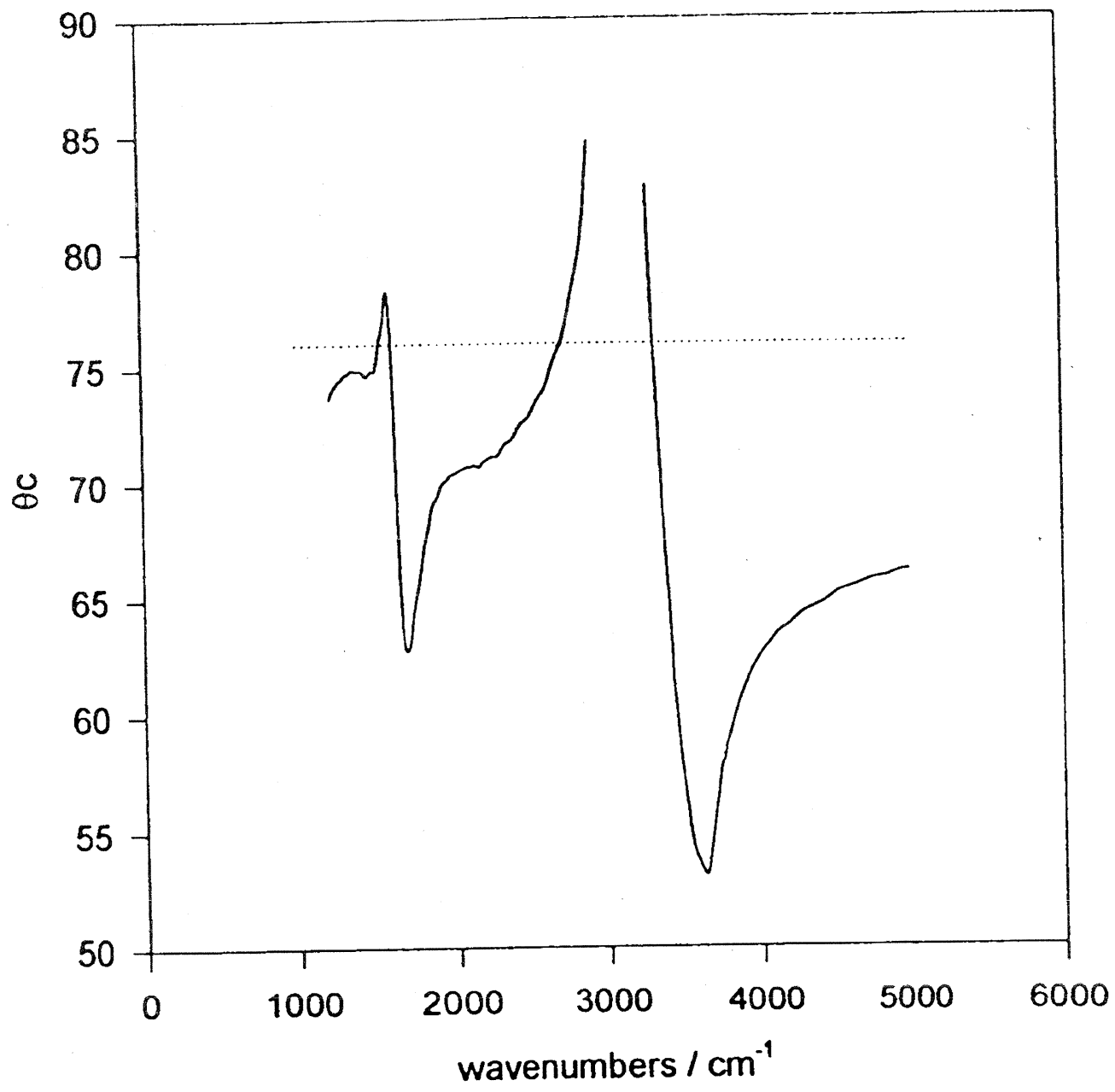

N.S.Marinkovic et al., "In situ Infrared Spectroscopic Investigations...", Figure 2. 

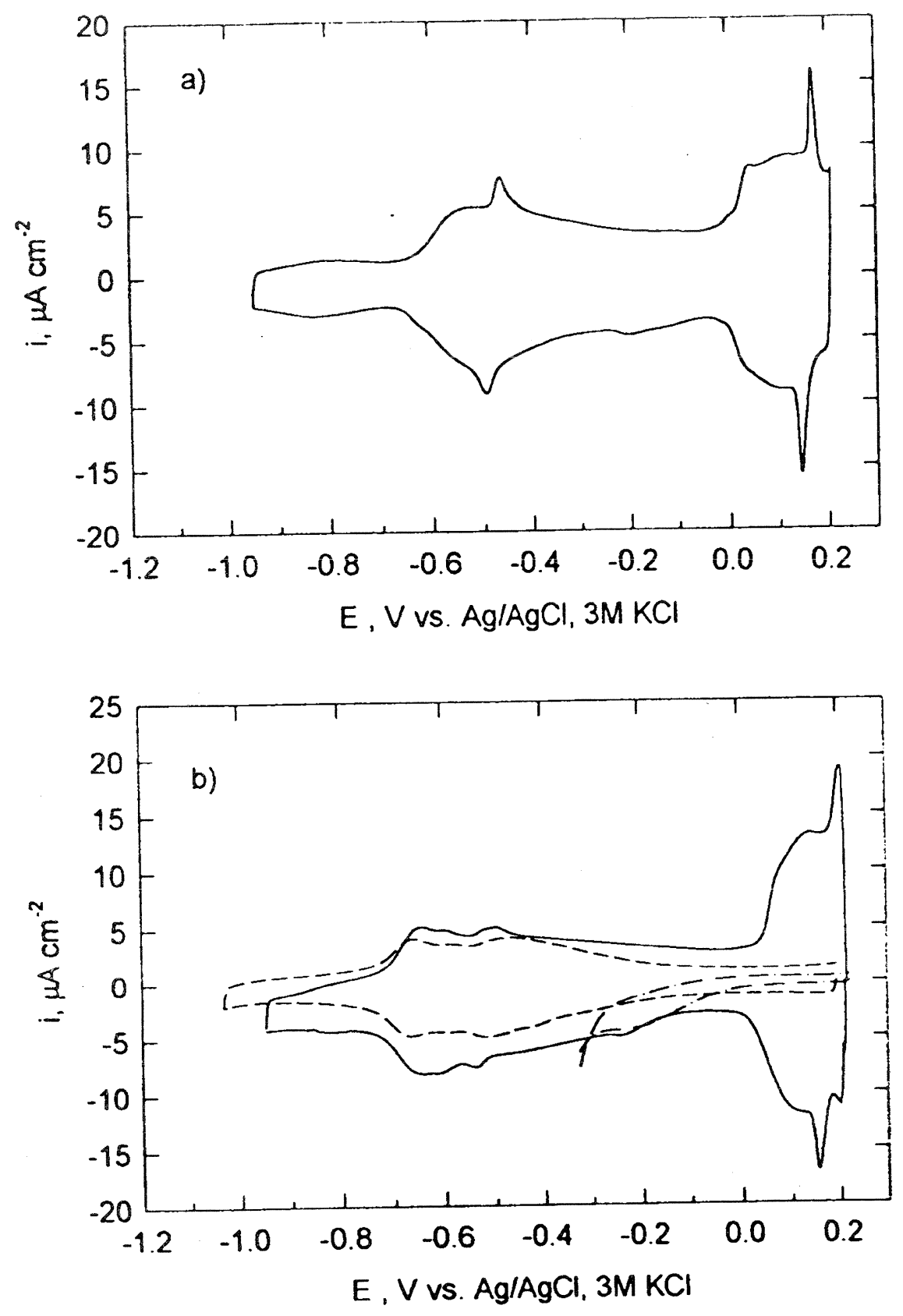

N.S.Marinkovic et al., "In situ Infrared Spectroscopic Investigations...", Figure 3. 


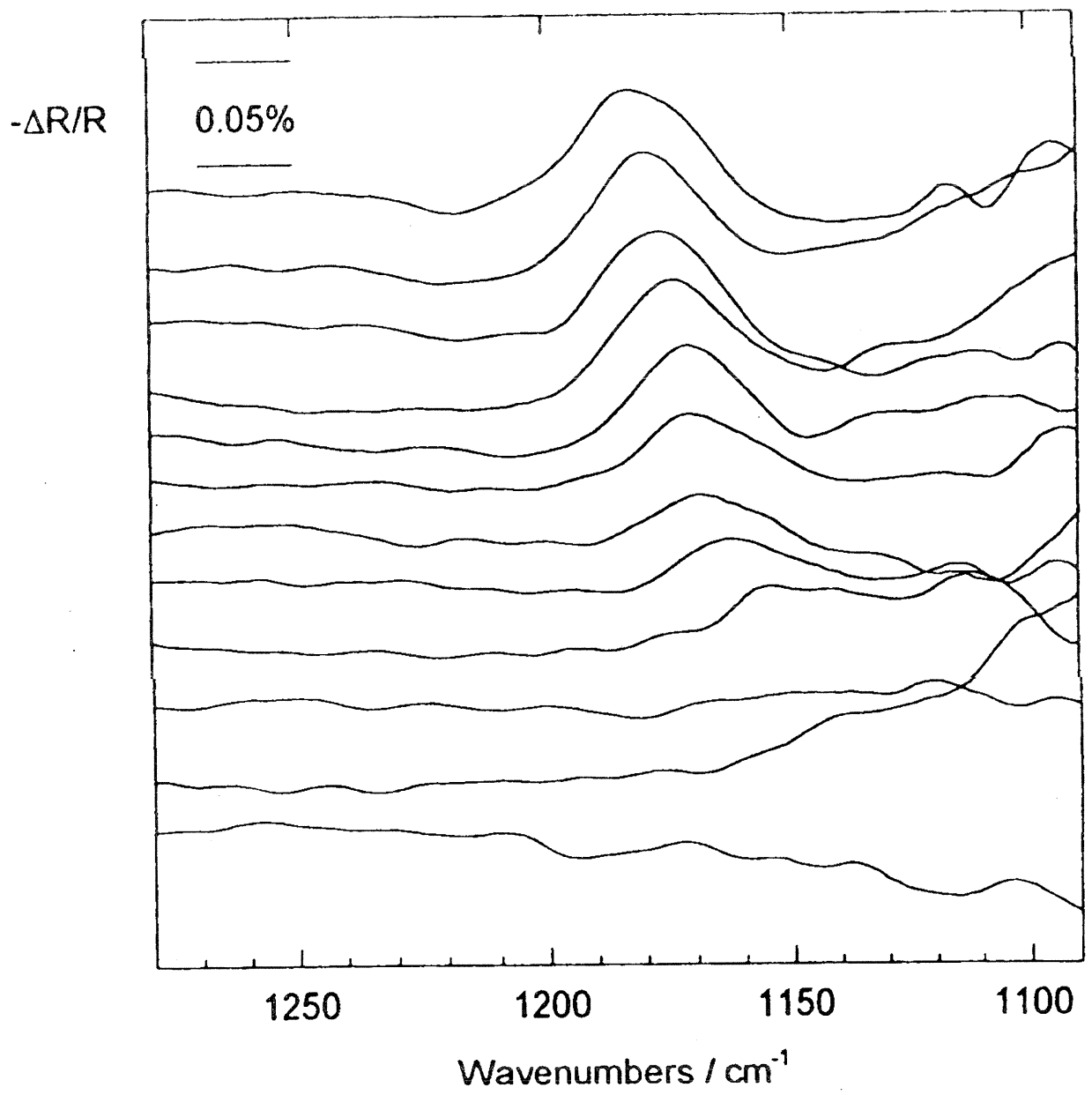

N.S.Marinkovic et al., "In situ Infrared Spectroscopic Investigations...", Figure 4. 

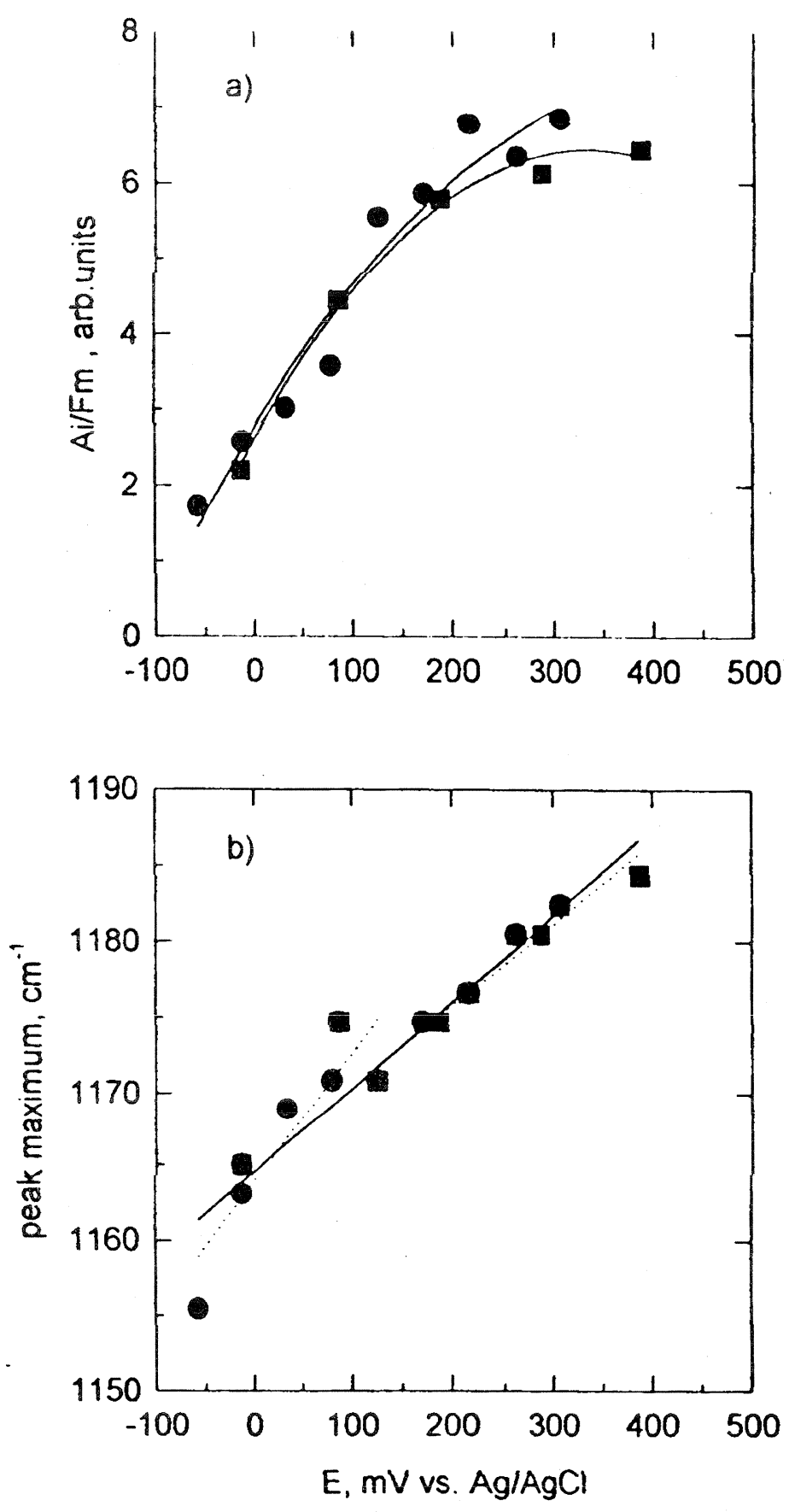

N.S.Marinkovic el al., "In situ Infrared Spoctroscopic Investigations...", Figure 5. 


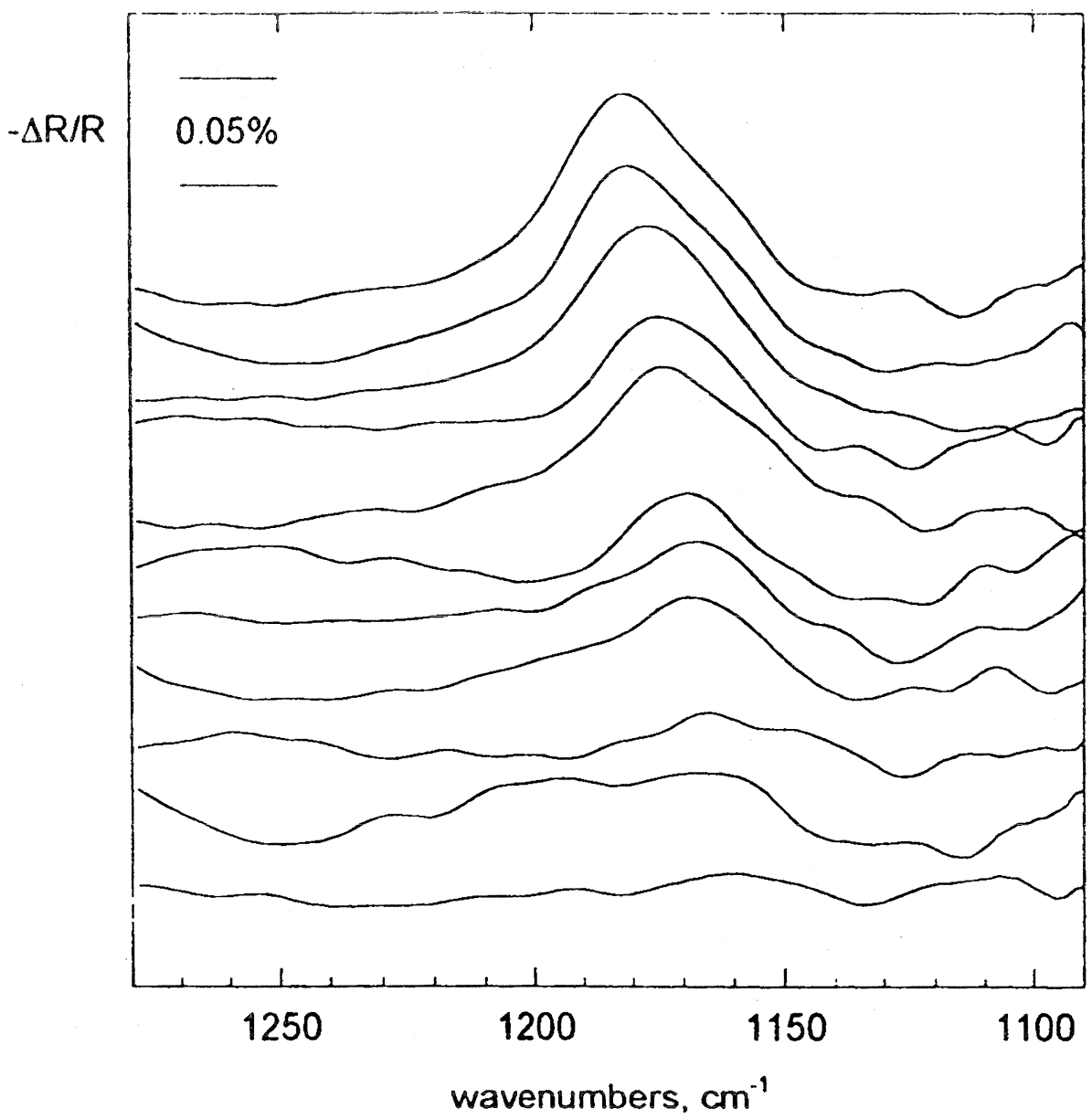

N.S.Marinkovic et al., "In situ Infrared Spectroscopic Investigations...", Figure 6. 

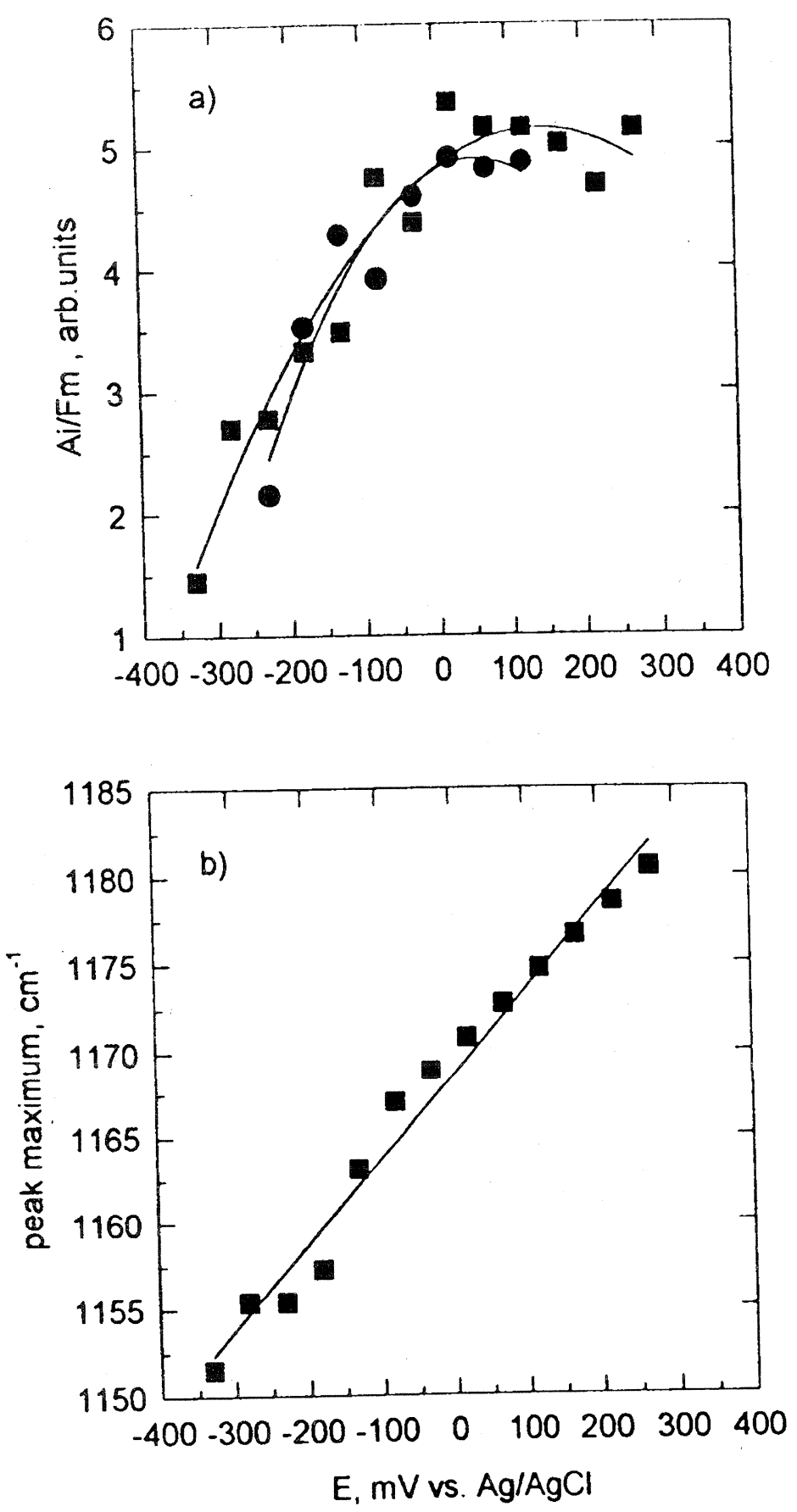

N.S.Marinkovic et al., "In situ Infrared Spectroscopic Investigations...". Figure 7. 


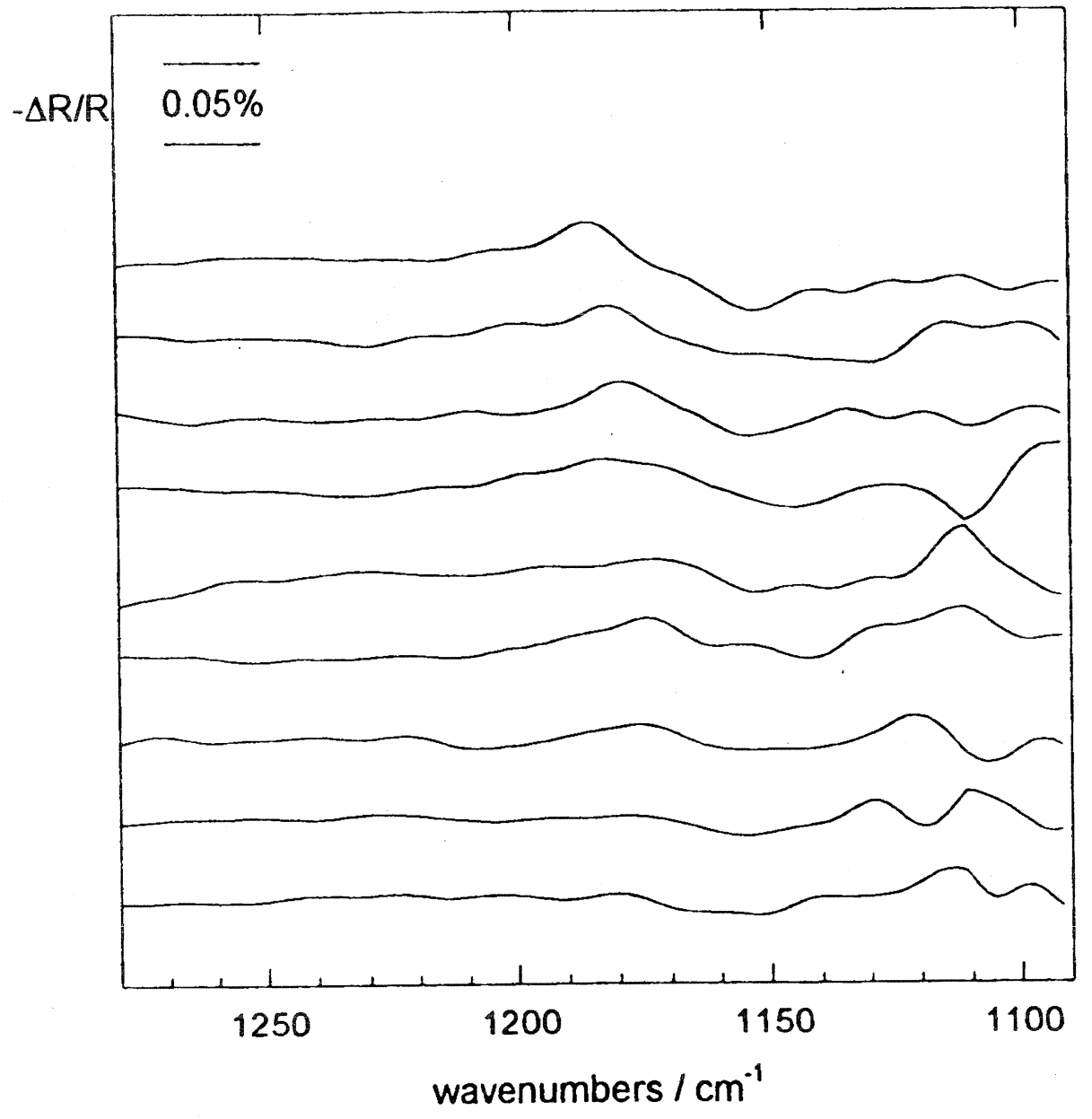

N.S.Marinkovic et al., “In situ Infrared Spectroscopic Investigations...”, Figure 8. 


\section{Methanol oxidation curves on different catalysts}

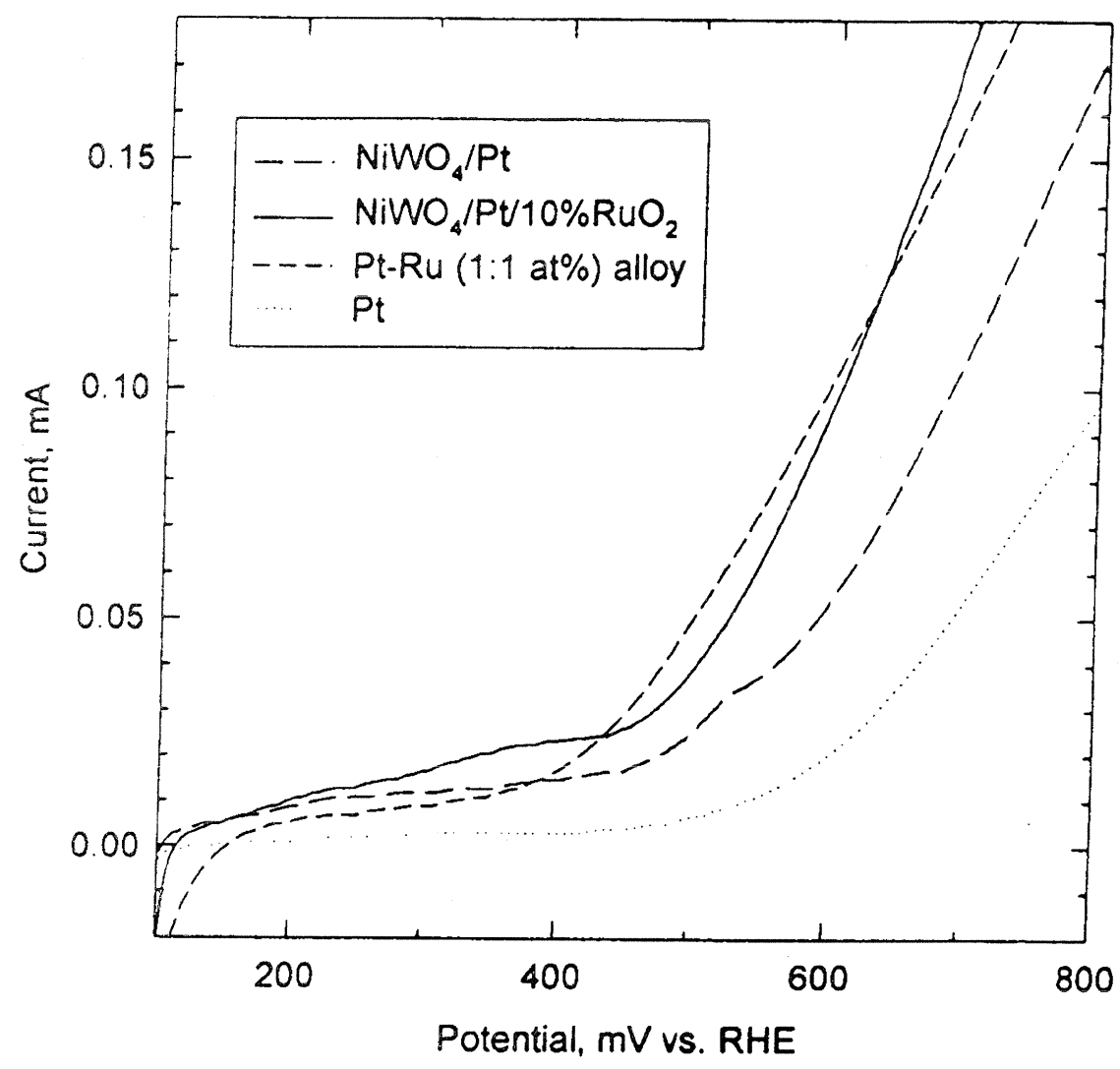

solution: $0.5 \mathrm{M} \mathrm{H}_{2} \mathrm{SO}_{4}+0.5 \mathrm{M} \mathrm{CH}_{3} \mathrm{OH}$;

approx. surface area: $1.42 \mathrm{~cm}^{2}$;

equal ammount of $\mathrm{Pt}$ in each catalyst;

all catalysts are supported by

Carbon(Vulcan) $/ 37 \%$ PTFE mixture. 


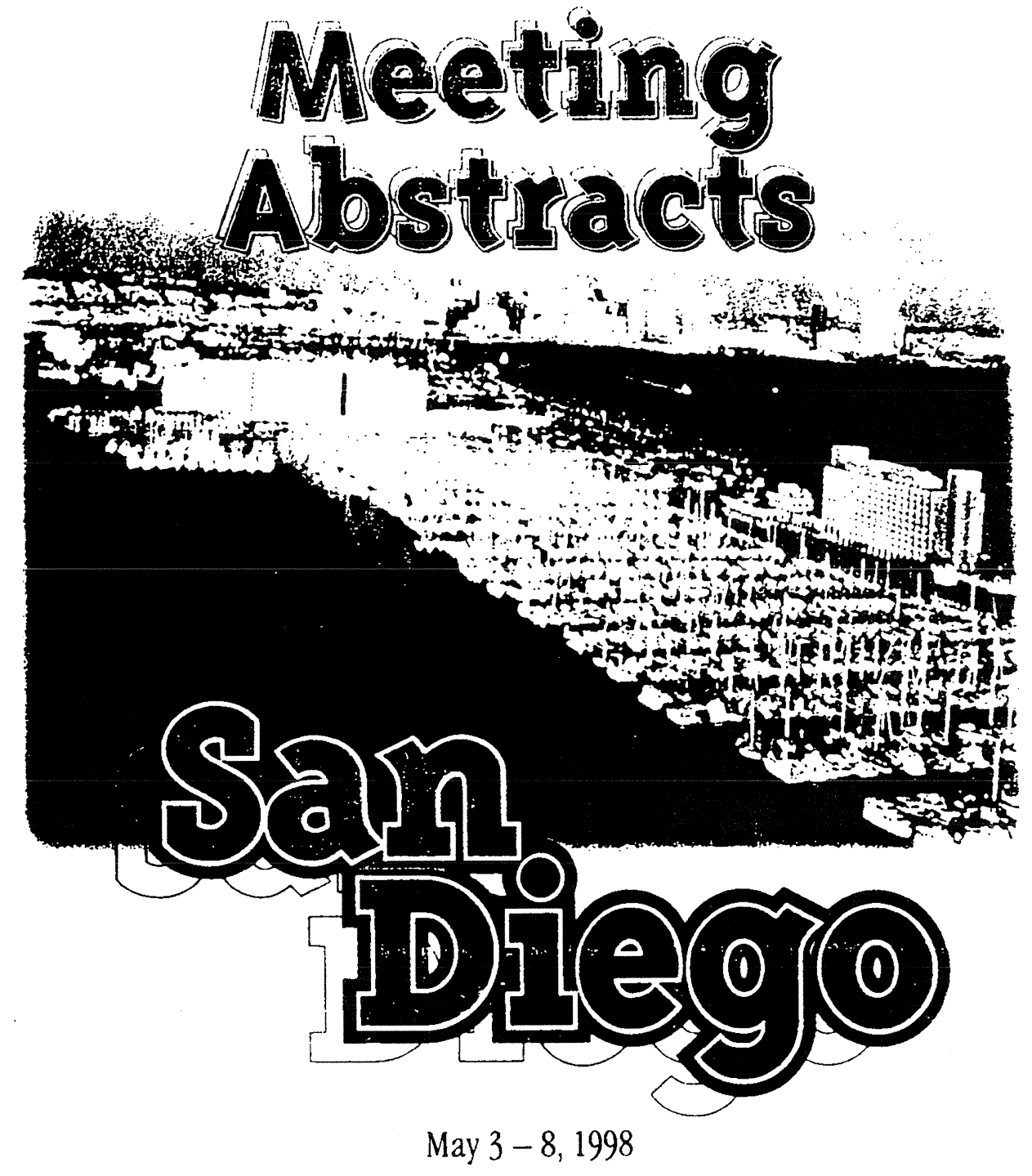

THE 193RD MEETING OF

The Electrochemical Society, Inc.

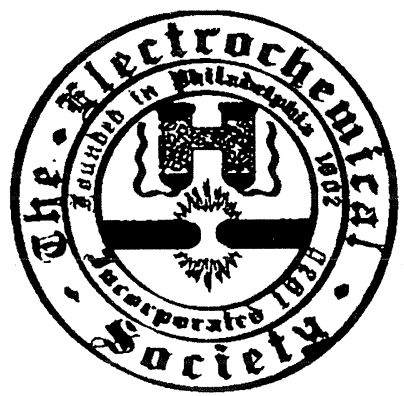


. Inary cuclusion that ic diffuse double layer inmential docay of the in exponential increase c from the electrode ure not far from those $170 \mathrm{~K})$, at which the ate (5)

meters of Electrode Butlerworths, London

oxek, J. Electroanal

leclrochem. Soc., 134,

Itman, N.C. Hung. 2

J. Elecirochem. Soc.

J. Electroanal. Chem.

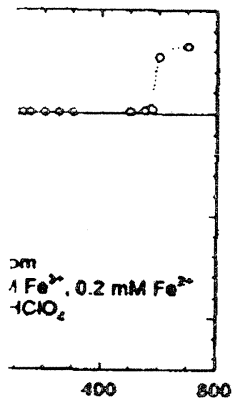

SEI INV

potential curve of the RDE. Potentials given vs. ztrode (MSE). Potential of \%. On this scale is $-0.46 \mathrm{~V}$

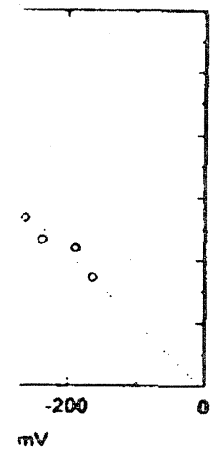

the logarithm of the of the $\mathrm{Fe}^{20} / \mathrm{Fe}^{2+}$ reaction
In situ spectroelectrochemical investigation of $\mathrm{CO}$ adsorption on underpotentially deposited silver at P(III) electrode

\section{N.S Marinkovic, J.X. Wang and R.R. Adzic}

Department of Applied Science, Brookhaven National Laboratory. Upton. NY 11973

$\mathrm{CO}$ adsorption on a metal poly- and monocrystalline surfaces has been one of the major subjects of surface science for decades (1). Upon adsorption on transition metal electrodes, the $C O$ stretching vibration is shown to be lowered from the gas phase value of $2138 \mathrm{~cm}^{-1}$. This behavior is explained in the Blyholder model by a weak electron transfer from So CO orbital followed by a stronger back-donation from the transition metal $d$-band into the $2 \pi^{*}$ CO orbital. In the case of IB transition metals, this back donation is of minor importance because of the low lying $d$-band. Therefore, $\mathrm{CO}$ is known to be physisorbed on bulk silver electrodes, and only an indication of a weak chemisorption is found (2). A chemisorption of $\mathrm{CO}$ has been reported on 30-atoms long Ag clusters, and the value of $\mathrm{CO}$ stretching frequency is found to be lowered to $2080 \mathrm{~cm}^{-1}$ (3). It is expected that even stronger shift to the red would be found on smaller $A_{8}$ clusters and especially on monolayer and bilayer $A_{8}$ electrodes.

Mono-and bilayers of silver on platinum electrodes have been obtained in the way described earliet (4). The spectroelectrochemical measurements were conducted in a custom made cell with a $\mathrm{ZnSe}$ hemispherical window (5), placed in an external chamber of a Mattson RS. 10000 spectrometer. PAR-273 potentiostat was used to set the potential of the working electrode altematively to the reference or the sample value.

Underpotential deposition of silver on P(111) cocurs in the potential region $0.65-1.2 \mathrm{~V}$ vs. RHE (4) in two seps. In solution of $1 \mathrm{mM} \mathrm{A8}+0.05 \mathrm{M} \mathrm{H}_{2} \mathrm{SO}_{4}$, the monolayer is formed in a broad potential region between 1.2 and $0.95 \mathrm{~V}$. The bilayer is formed at $0.69 \mathrm{~V}, 30 \mathrm{mV}$ before the onset of bulk deposition (4). When this solution is sarurated with $\mathrm{CO}$, the cyclic voltammogram in Figure 1 shows that the electrochemical oxidation proceds at the UPD monolayer of $\mathrm{Ag}$ in a wide potential region. In the anodic scan, the $\mathrm{CO}$ oxidation commences at $0.9 \mathrm{~V}$ and shows a maximum at $1.07 \mathrm{~V}$. In the cathodic direction, the $\mathrm{CO}$ oxidation takes place in a potential region that extends up to the onset of bilayer formation.

Fie 2 shows the in-situ adsorption and electrooxidation spectra of $\mathrm{CO}$ at the silver monolayer at a Pu(111) electrode. The reference scan was taken at $u . i$ $V$. just before the onset of bilayer formation, and the sample scans were taken at more positive potentials, staring from $0.8 \mathrm{~V}$ and incremented by $0.1 \mathrm{~V}$. A bipolar band with a negative lobe at $2020 \mathrm{~cm}^{-1}$ and a positive one a $-2050 \mathrm{~cm}^{-1}$ arises as a consequence of a $\mathrm{Cm}$ sretching frequency change when the porential is switched from the reference to the sample value. The positive lobe appears to shift to higher frequencies as the electrode potential is made more positive. At the potentials higher than $1.0 \mathrm{~V}$, a sharp, positive-going band at $2343 \mathrm{~cm}^{-1}$ appears in the spectra due to the $\mathrm{CO}_{2}$ formation at the electrode surface.
These results clearly indicate that the $\mathrm{CO}$ is chemicorbed on $A_{8}$ monolayer in a potential region that extends up to the onset of $\mathrm{Ag}$ bilayer formation, and is oxidized at potentials more positive than $0.9 \mathrm{~V}$. Its chemisorption and oxidation can be easily followed by means of in situ spectroelectrocheinistry

\section{References:}

1. F.M.Hofinann, Surf.Sici.Reports, 3 (1983) 107

2. W.Hanson, M.Bertolo and K.Jacobi, Surf.Sci, 253

(1991) 1.

3. F.W.Froben, I.Rabin, M.Riz and W.Schultze, Z.Phys.

D. 335 (1996) 338.

4. N.S.Marinkovic, J.X.Wang and R.R.Adzic, in: "The Electrochemical Double Layer". Proc. Electrochem. Soc., Vol. 97-17, Pennington, NJ (1997).

5. N.S.Marinkovic, J.S.Loring, M.Hecht and

W.R.Faucett. Electrochim.Acta. 41 (1996) 641.

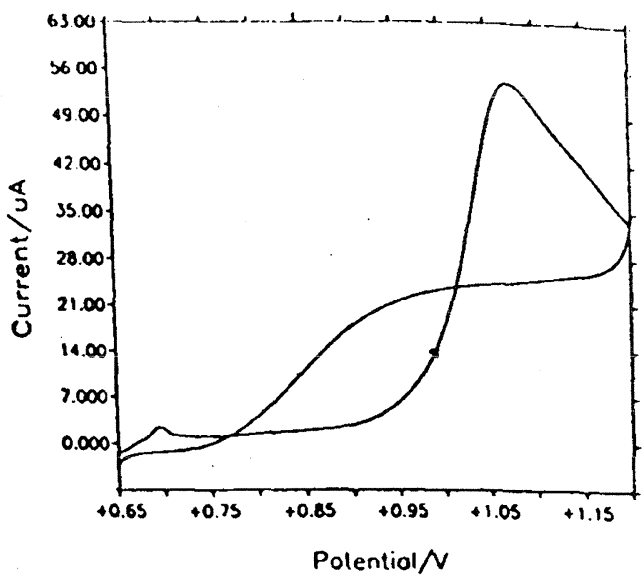

Figure 1. Cyclic voltammetry of $\mathrm{CO}$ oxidation on the monolayer of silver deposited at a $\mathrm{P}(1111)$ in a $\mathrm{CO}$

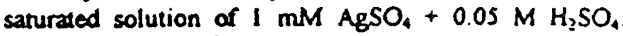
Sweep rate $2 \mathrm{mV} \mathrm{s}$.

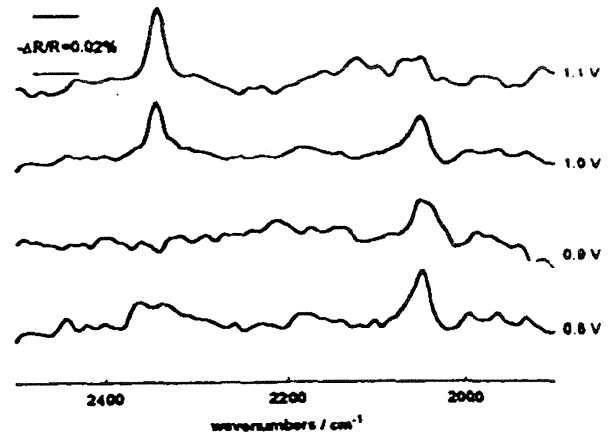

Figure 2. SNIFTIRS spectra of $\mathrm{CO}$ adsorptionloxidation on the UPD $\mathrm{Ag} / \mathrm{Pt}(111)$ in CO-sauturated solution of 1 mM AgSO, + 0.05 $\mathrm{M} \mathrm{H}_{2} \mathrm{SO}_{4}$. Reference scan was taken at potential of $0.7 \mathrm{~V}$, and sample scans were taken at potentials as indicaled in the figure. 768 scans. $8 \mathrm{~cm}^{-1}$ resolution, $p$ polarization. 